\title{
Early 21 st Century Glacier Thickness Changes in the Central Tien Shan
}

\author{
Jia $\mathrm{Li}^{1}$, Zhi-wei $\mathrm{Li}^{1 *}$, Jian-jun Zhu ${ }^{1}$, Xin $\mathrm{Li}^{2}$, Bing Xu${ }^{1}$, Qi-jie Wang ${ }^{1}$, Chun-lin Huang ${ }^{2}$, Jun $\mathrm{Hu}^{1}$
}

\begin{abstract}
Although studies based on satellite gravimetry (2003-2010) and laser altimetry (2003-
\end{abstract} 2009) measurements have achieved region-wide glacier mass change for the Tien Shan, the dynamic process of glacier yet to be closely monitored and understood so that its impact can be assessed accurately. In this study, we investigated region-wide glacier thickness change in the Central Tien Shan (CTS) during 2000-2012 by differencing the Shuttle Radar Topographic Mission (SRTM) digital elevation model (DEM) with a newly constructed DEM from 27 TanDEM-X images. For a total glacier area of $7239.8 \pm 527.2 \mathrm{~km}^{2}$, an average glacier thickness change rate of $-0.24 \pm$ $0.22 \mathrm{~m} / \mathrm{a}$ was derived. This result agrees well with the result based on satellite laser altimetry measurements reported earlier $(-0.31 \pm 0.41 \mathrm{~m} / \mathrm{a})$. With temporal synchronization, a fine spatial resolution and wide coverage, our measurements are able to reveal abundant glacier change features and dependencies in the CTS. Firstly, the lower mountains have seen a more severe glacier decline, and the glaciers facing the prevailing wind (westerlies) have experienced a greater decline because of the stronger evaporation. Furthermore, those glaciers lying along the extremely high Meridian mountain range have obviously gained mass in their upper reaches, because the air current from the west is blocked and lifted by the Meridian mountain range. Secondly, for the entire glacier body, the theoretical hyperbolic dependence between debris thickness and ice decline was very difficult to establish. Some huge glaciers covered by heavy debris have still experienced a severe decline. However, even though the heavy debris did not prevent the ablation, its attenuating effects were considerable. Thirdly, for the glaciers that surged before 2000, the mass gain in the restoring zones has not been enough to cover the mass loss in ablation zones. Some large glaciers surged again 
during 2000-2012; however, with much lower magnitudes than in previous surges. In general, the surge glaciers have experienced a greater decline than the non-surge glaciers. Fourthly, due to the ice front calving and subglacial thermal erosion, glaciers connected to proglacial lakes have receded and thinned much more rapidly than the land-terminated glaciers. Overall, the glaciers in the CTS are more stable than those in other parts of the Tien Shan. However, the glacier state there is still alarming. A moderate average thinning rate was derived because the drastic thinning in the ablation zones was balanced by the slight thinning in the broad accumulation zones.

Keywords CTS, TanDEM-X, glacier, thickness change, surge, debris

\section{Introduction}

meltwater serves as a vital fresh water resource, constant deglaciation since the 1980s has placed both the local societies and ecosystems under pressure (Li et al., 2008; Yao et al., 2012). Meanwhile, glacial hazards become increasingly frequent after glaciers lose substantial mass, such as floods and mudslides. Major social issues involving mountain glaciers are how much influence the glacier change will make and how long the glaciers will remain on the mountains. Technically, these issues can be answered by the region-wide glacier mass balance; more precisely, the representative thickness change magnitude and the high-resolution thickness change maps. Therefore, since the beginning of systematic glacier study, thickness change measurement has always been the major undertaking of glaciologists.

The Tien Shan is known as the 'Water Tower of Central Asia'. According to the latest version of the Randolph Glacier Inventory (RGI5.0) (Arendt et al., 2015), the glaciated area in the Tien Shan covers $\sim 11856.4 \mathrm{~km}^{2}$ in total (not including the $520.9 \mathrm{~km}^{2}$ of the Dzhungar Alatoo). The Tien Shan can be divided into five parts, i.e. Northern, Western, Eastern, Inner and Central (see Fig. 1). The glaciated area within the CTS amounts to $56.6 \%$ of the glaciated area of the Tien Shan. Clearly, among the five sub-regions, the CTS plays a dominant role in terms of glaciation. The CTS 
peripheral forelands are basically arid. Taking Aksu (a prefecture-level city located between the CTS and the Takla Makan Desert) as a typical example, it receives precipitation of only $60-80 \mathrm{~mm}$ per year. Nevertheless, Aksu serves as a significant commodity grain and cotton base of China, and is regarded as an area of high-quality fruits. It is the glacial meltwater flowing from the CTS that provides most of the fresh water supply of the peripheral forelands, especially in dry summers (Sorg et al., 2012). Owing to the abundant glacial meltwater, the CTS peripheral forelands played a pivotal role in the ancient 'Silk Road', and have become a densely populated area with prosperous multicultural exchange. However, there is some evidence that the glaciers in the CTS are undergoing significant changes (Pieczonka et al., 2013; Pieczonka and Bolch, 2015; Shangguan et al., 2015). Hence, region-wide glacier thickness change measurement in the CTS is of great importance for both local hydrological policy making and an input to glaciological modelling.

Conventional thickness change measurements, such as Global Position System (GPS) surveys, stake records and ground radio echo sounding, are directly conducted on the ice fields. Undoubtedly, such field measurements can acquire accurate information. However, due to the vast extent of the glaciers, the great altitude variation and the difficult logistics, conventional thickness change data are still scarce. To the best of our knowledge, in the CTS, only seven glaciers have been measured via conventional methods (see Table 1). Mathematical extrapolation or glaciological modelling based on inadequate and uneven observations can result in great uncertainty, since glacier changes are subject to many local factors, e.g., altitude, location, orientation, surge activity, debris cover and glacial lakes. In terms of large-scale thickness/mass measurements in polar ice sheets, satellite laser altimetry and gravimetry are efficient and suitable approaches (Sørensen, et al., 2011; Gardner et al., 2013). However, in terms of small-scale mountain glacier monitoring, the rough spatial resolution of satellite gravimetry and the sparse spatial coverage as well as large footprint size of satellite laser altimetry limit the reveal of thickness change features and dependencies. To date, to the best of our knowledge, three teams have measured the Tien Shan glacier thickness/mass changes via satellite laser altimetry or gravimetry, i.e., Jacob et al (2012), Gardner et al. (2013) and Farinotti et al. (2015). 
These teams focused on deriving representative glacier thickness changes, and only Farinotti et al. (2015) presented sub-regional thickness changes by dividing the Tien Shan into seven sub-regions.

\begin{tabular}{|c|c|c|c|c|}
\hline Glacier & Time & Method & $\begin{array}{c}\text { Mass Balance } \\
\text { (m/a w.e.) }\end{array}$ & Data source \\
\hline Sary-Tor & 1985-1989 & Stake record & -0.14 & WCMS, 1991 \\
\hline Kara-Batkak & 1957-1998 & Stake record & -0.44 & WGMS, 1999 \\
\hline Suek Zapadniy & $2010-2013$ & Stake record & -0.37 & WCMS, 2015 \\
\hline Akshiirak No.354 & $2010-2013$ & Stake record & -0.38 & WCMS, 2015 \\
\hline Gregoriev & $2006-2007$ & GPS survey & -0.25 & Fujita et al., 2011 \\
\hline Qingbingtan No. $72^{\mathrm{a}}$ & 1964-2008 & $\begin{array}{c}\text { Photogrammetry in } 1964 \text { and } \\
\text { GPS survey in } 2008\end{array}$ & -0.20 & Wang et al., 2011 \\
\hline
\end{tabular}

\footnotetext{
${ }^{\mathrm{a}}$ The mass balance is limited to glacier tongue.

${ }^{b}$ The measurements were available at only two cross profiles of glacier tongue.
}

Through the use of optical or synthetic aperture radar (SAR) images, we can derive the regionwide glacier thickness changes via geodetic measurement, i.e., generating a new DEM via photogrammetry or interferometric SAR (InSAR) and then comparing it with a historical one. Characterized by the high spatial resolution, geodetic measurement has great advantages in revealing glacier change details, especially glacier surge. At present, in the CTS, most of the airborne photogrammetry based geodetic measurements were obtained during the 1940s-1970s (military use) and have not been fully declassified. Only the thickness changes of the Arshiirak mountain range glaciers (1943-1977 and 1977-2000) and the Qingbingtan No. 72 glacier (1964-2008) have been measured via airborne photogrammetry (Aizen et al., 2007; Wang et al., 2011). With the declassification of some optical reconnaissance satellite stereo images, e.g., CORONA/KH-4/4A/4B (from 1962) and its successor HEXAGON/KH-9 (from 1971), the time span of investigations based on spaceborne photogrammetry can be 40-50 years (Bamber and Rivera, 2007; Pieczonka et al., 93 2013; Pieczonka and Bolch, 2015). However, cloud cover, which is common in glaciated regions, can significantly degrade the quality of the optical images. Consequently, region-wide thickness 
change measurements obtained via spaceborne photogrammetry based geodetic measurements are still temporally or spatially limited in the CTS. The 1975-1999 CTS region-wide glacier mass changes, the 1976-2009 Tuomuer Mountain southwest slope glacier mass changes and the 19742007 Inylchek glacier mass changes were measured using Hexagon/KH-9, ALOS/PRISM and SPOT5/HRG stereo images, respectively (Pieczonka and Bolch, 2015; Pieczonka et al., 2013; Shangguan et al., 2015). However, the early 21st century region-wide thickness change of the CTS has not yet been derived by geodetic measurement. In addition, the previous studies have been concerned with the magnitude of the glacier thickness/mass change, climate consideration and runoff contribution, but they have rarely interpreted region-wide glacier thickness change features and dependencies in the CTS. Moreover, elevations in glacier accumulation zones, where the surface has high albedo, can be difficult to obtain by photogrammetry because of low image brightness contrast. By installing stakes around the summit (the accumulation zone) of the Gregoriev glacier, Fujita et al. (2011) reported that the average surface height change of the eight points was $+0.185 \mathrm{~m}$ in one year (2006-2007), which is considerable.

Although InSAR can work regardless of cloud and surface brightness contrast, it is susceptible to variations in atmosphere characteristics and target de-correlation. The widely applied SRTM DEM is a global DEM derived by single-pass dual-antenna InSAR within only 11 days in February of 2000 (Farr and Kobrick, 2000). The key to SRTM's success is the excellent coherence assured by the synchronous acquisition of master and slave images. Most SAR sensors (e.g., ERS1/2, ENVISAT, ALOS/PALSAR1/2, RadarSat1/2, COSMO-SkyMed, TerraSAR-X) need a revisit to collect the image pair for interferometry. Even when the revisit interval is as short as 1 day (ERS1/2 tandem mission), the backscatter signals of a mountain glacier surface may be decorrelated due to the ablation and recrystallization. More importantly, the phase differences will contain some parts that have been affected by glacier motion and atmospheric variation. Since glaciers move continuously and the atmosphere varies frequently, it is difficult to extract precise glacial elevation from the repeat-pass SAR image pairs. Therefore, SAR images have been mostly applied to measure glacier 
motion change (Li et al., 2014), and for mountain glaciers the exact thickness changes are difficult to

derive by measuring motion change. The German Aerospace Centre (DLR) started a new InSAR mission in 2010. In this mission, two satellites, TerraSAR-X (TSX) and TanDEM-X (TDX), were launched successfully and formed a constellation. This mission is designed to derive a new global DEM through the innovative two-pass bistatic interferometric mode, i.e., either the TSX or TDX satellite sends out a microwave signal, and then the scattered echo is received by the two satellites simultaneously. Technically, the characteristics of imaging with a high spatial resolution, and being independent of surface brightness contrast, cloud cover, glacier motion and atmospheric variation, as well as the uniformity of the image acquisition time and the full spatial coverage, enable the TanDEM-X mission to derive precise region-wide glacial elevations. In fact, one primary objective of the TanDEM-X mission is to provide accurate surface topography for measuring glacier thickness/mass changes (Hajnsek et al., 2010). In this study, we adopt the TanDEM-X images and SRTM DEM to study the region-wide mountain glacier thickness change in the CTS. In addition to the representative glacier thickness change rates, abundant glacier change features and dependencies are revealed.

\section{Study Area}

The Tien Shan is one of the longest mountain ranges in Central Asia (Liu et al., 1998). In accordance with previous studies, the mountains in the range of $77^{\circ} 22^{\prime} \sim 83^{\circ} 47^{\prime} \mathrm{E}$ and $40^{\circ} 33^{\prime} \sim 43^{\circ} 50^{\prime} \mathrm{N}$ can be allocated to the CTS (see Fig. 1) (Kutuzov and Shahgedanova, 2009; Narama et al., 2010; Sorg et al., 2012; Unger-Shayesteh et al., 2013; Pieczonka and Bolch, 2015). From west to east, it can be divided into three massifs: ETASAKEK (East Terskey-Alatoo, Suek, Akshiirak, Koilu and East Kakshaal), HHKTXT (Hadtior, Harajoriha, Khan Tengri, Xuelian and Tuomuer) and BHT (Biyeek and Halk Tawu). In ETASAKEK and BHT, the mountain ranges are separated by non-glaciated valleys. We further group the glaciers according to the mountain range extent. However, in HHKTXT, the mountain ranges are separated by glacier beds. Referring to previous reports (Su et al., 1985; Pieczonka et al., 2013), we further group the glaciers based on 
147 mountain range orientation. The major mountain ridges are considered as boundaries of the sub148 regions (i.e. the Intermontane Basin, Northern Slope and Southern Slope, see Figs. 1 and 5). 149 Extremely high topography and abundant precipitation enable the CTS to develop large-scale 150 glaciers. In the central zone (i.e. the Tuomuer-Khan Tengri mountain range), more than 40 peaks are 151 above $6000 \mathrm{~m}$ a.s.l. (Su et al., 1985). The moisture in the CTS is mainly brought by the westerlies. 152 The annual precipitation in the glacier accumulation area (5200-5250 $\mathrm{m}$ a.s.1.) can be as much as $1531000 \mathrm{~mm}$. Moreover, $70 \%$ of the annual precipitation occurs between May and September, i.e., the 154 glaciers here are the summer-accumulation type. In general, the precipitation is greater in the west 155 slope than in the east slope, and in the north slope than in the south slope. From high mountains to 156 piedmont, the precipitation decreases by approximately $30 \mathrm{~mm}$ per $100 \mathrm{~m}$ altitude (Su et al., 1985). 157 The distribution of natural vegetative cover presents vertical zonality. In the forelands below $2000 \mathrm{~m}$ 158 a.s.l., desert grasslands and bush dominants, while over the hillsides between $2200 \mathrm{~m}$ a.s.l. and 4000 159 m a.s.l., snowy spruce and subalpine meadow grow well (Sun et al., 2012). Rivers fed by the CTS 160 glaciers are major tributaries of the Tarim, Ili and Syr Darya, three prominent inland rivers of Central 161 Asia. Hence, the CTS glaciers also play a significant role in maintaining the ecosystem balance of 162 Central Asia. 


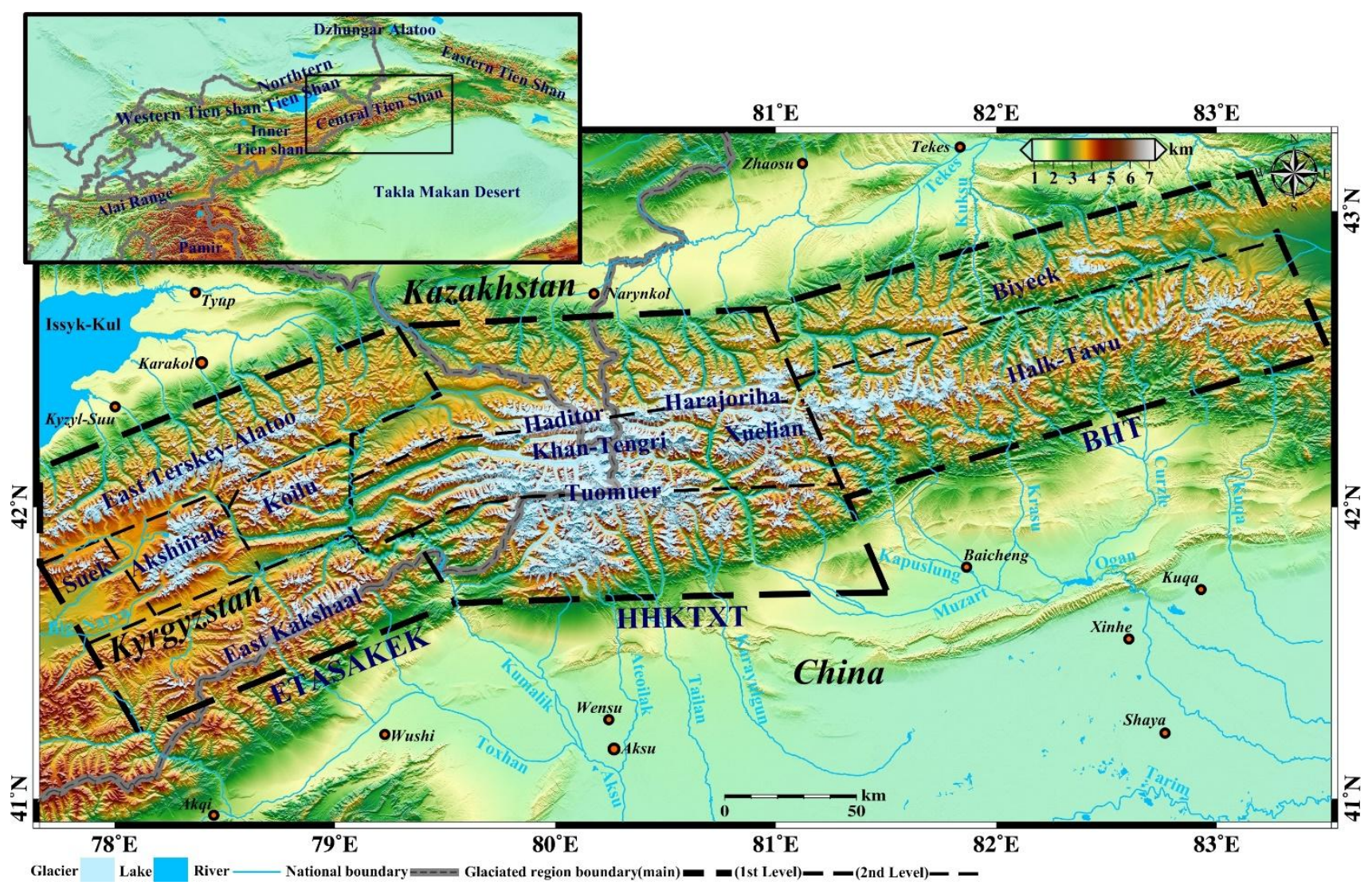

Fig. 1. Hydrology and topography in the Central Tien Shan. Names of the mountain ranges are shown in deep blue.

The thickest dashed line polygon represents the measured glaciated region. Glaciers within it are separated into 3

1st level (ETASAKEK, HHKTXT and BHT) and 10 2nd level sub-regions. Note that the separation of sub-regions

in HHKTXT is based on mountain orientations rather than mountain ranges. The insert panel shows the approximate location of the Central Tien Shan.

\section{Data and Methods}

\subsection{DEMs}

The DEMs acquired in 2000 and 2012 were utilized to measure the glacier thickness change.

172 The C-band SRTM DEM was employed as the benchmark elevation. Its nominal relative/absolute

173 vertical and horizontal accuracy are 6/16 m and 15/20 m, respectively (with $90 \%$ confidence level)

174 (Rabus et al., 2003). In 2006, Rodríguez et al. reported that 90\% of the Eurasia SRTM has an

175 absolute horizontal error of less than $8.8 \mathrm{~m}$ and a vertical error of less than $6.2 \mathrm{~m}$. As a result of the

176 data acquisition consistency and accuracy, it has been proved to be a good benchmark DEM for

177 glacier thickness change measurement in previous studies (Berthier et al., 2007; Nuth and Kääb, 
2011). The elevation has already been referenced with WGS84 datum and EGM96 geoid. The original pixel size is 1 arc seconds, and in our study area, it is equal to $\sim 23.0 \mathrm{~m}$ and $\sim 30.9 \mathrm{~m}$ under UTM projection (zone 44N) in the north and east directions, respectively.

The new DEMs were generated from the TanDEM-X interferometric images. For the TanDEM-X mission, three cooperative modes are adopted for interferometric data, i.e., Bistatic, Pursuit Monostatic and Alternating Bistatic. Meanwhile, the TanDEM-X mission has three imaging modes: StripMap, ScanSAR and SpotLight. However, only the bistatic StripMap mode is used to derive the standard global TanDEM-X DEM. For more details about the TanDEM-X mission, refer to Hajnsek et al. (2010). The distributed TanDEM-X product is the coregistered slant range single look complex (CoSSC) image pair, which is ready for interferometry. In this study, 27 bistatic with an azimuth and ground range resolution of $3.3 \mathrm{~m}$ and $1.7-3.5 \mathrm{~m}$ (corresponding to a $45-20^{\circ}$ incidence angle), respectively. Details of the 27 CoSSCs can be found in Table 2.

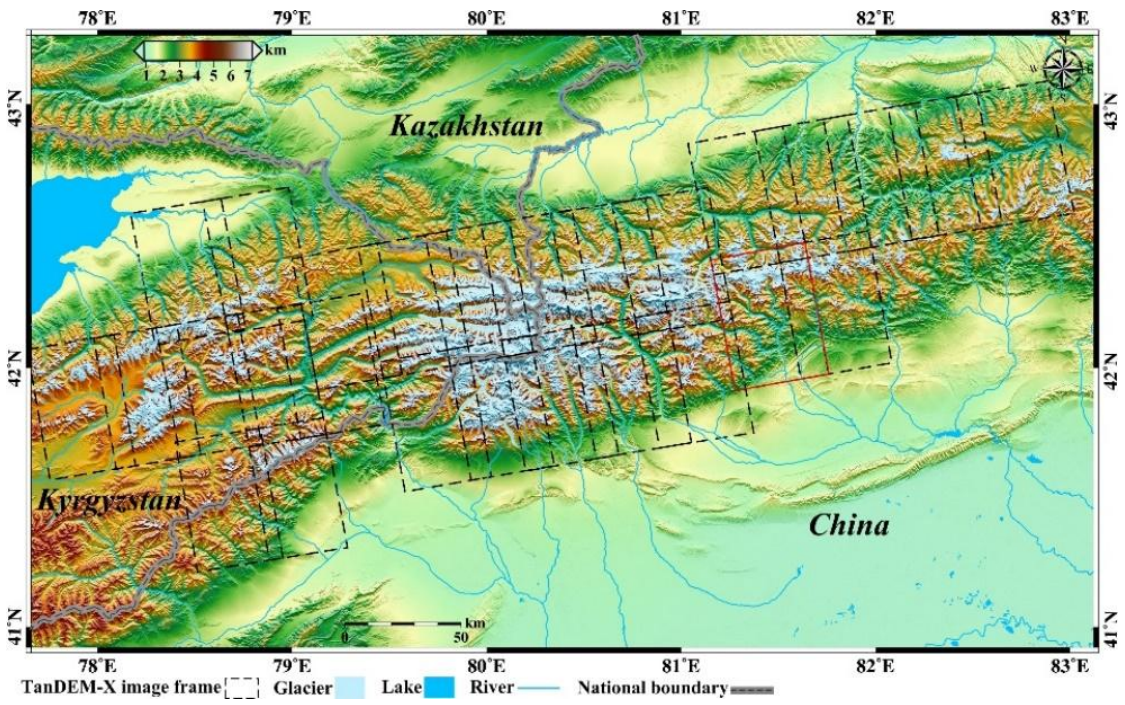

Fig. 2 TanDEM-X image frames. 
The TanDEM-X DEMs were produced via the differential interferometry method. Basic 197 procedures included interferogram generation, external DEM (SRTM DEM) coordinate 198 transformation, phase simulation, phase subtraction, interferogram filtering, phase unwrapping, 199 height retrieval, height addition and DEM geocoding. Among these procedures, the phase simulation 200 and height retrieval took the bistatic geometry and zero Doppler Time into account. In order to 201 simplify the phase unwrapping, the original interferogram phase was differenced with that simulated 202 from the SRTM DEM (containing flat-earth phase) in advance. During the phase unwrapping, a 203 reference point was chosen from the non-glaciated region and set as the zero phase point. The height 204 difference was then retrieved from the absolute phase difference. By adding the height difference to 205 the oversampled SRTM DEM and transforming the Range-Doppler coordinates of the SAR height into map coordinates, we obtained the new DEM. In this case, our new DEMs are relative and share the same geographical reference as the SRTM DEM. However, what we need is the height difference between the new DEM and the SRTM DEM. A total of 27 TanDEM-X DEMs were produced.

\subsection{Glacier Outlines}

Glacier outlines are essential for deriving regional glacier thickness changes. Referring to RGI 5.0, we delineated the glacier outlines from the Landsat L1T images acquired around 2000, and further edited them with the assistance of other information (Albert, 2002; Paul et al., 2013). Due to the wide range, six standard Landsat frames (in three tracks) were needed to cover the study area. In order to minimize the impact of the snow, images acquired at the end of the melting season were preferred. Regarding the image acquisition time and shadow/cloud/snow proportion, we collected 17 suitable Landsat L1T images acquired on nine different days for the glacier delineation (18 1 August 2013, 31 August 2013 and 25 September 2013, see Table 2).

The band ratio method was adopted for the automatic glacier outline delineation. This simple but robust method is regarded as the most suitable for mountain glacier classification (Albert, 2002; 
222

223

224

additional threshold on the band1 DN to classify the surface objects into two types: glacier and nonglacier. This band combination can distinguish ice and snow in cast shadow, but may misclassify water surface as glacier body. However, the water surface can be easily remedied by manual interpretation. After the automatic classification, the binary maps were converted into polygon vectors for post-editing. Comparing the images obtained on two adjacent dates is an effective way to distinguish most seasonal snow and cloud from the glacier body. Images with the least cloud were adopted for the automatic extraction of the glacier outlines (5 August 2000, 18 August 2002 and 25 August 2002). The other images were employed as references during the post-editing. Glaciers that had surged or advanced could be correctly delineated with the images acquired in 2013. To facilitate the post-editing, the vector map was overlapped with the Landsat multispectral-panchromatic fused images (15 m pixel size), the terrain slope and aspect map, and the glacier velocity and thickness change map. Since most of the glaciers in the CTS have debris-covered tongues, the post-editing was a time-consuming but non-trivial task.

We determined the glacier outlines under the debris via three steps. Firstly, the slope threshold and visual interpretation were applied. Kääb (2005) suggested that the areas with slopes lower than the threshold $\left(23^{\circ}\right)$ and directly connected with the clean ice could be regarded as debris-covered ice. This is quite useful when delineating the lateral outlines. Due to the underlying ice flow, the ice cliffs/falls and the uneven ablation, the supraglacial debris has a loose and rugged surface, while the proglacial moraine (unsorted till) and sediment (sorted till) in the outwash plain appear compact and smooth (Evans and Gooster, 2005). Meanwhile, the colour of supraglacial debris is distinct from that of proglacial till, and the supraglacial debris of the whole glacier tongue basically has similar spectral properties. Secondly, as all glaciers are moving, the active parts within the bed in the glacier velocity maps can be considered to be the glacier body (Kääb, 2005). The glacier velocity maps derived in previous studies were adopted to extract the active parts of the glaciers ( $\mathrm{Li}$ et al., 2014). However, in practice, the precision of the motion detection is limited, which means that this criterion is applicable only for the fast-flowing glaciers. If the slow-flowing glaciers have their tongues covered by thin 
248 debris, they are difficult to delineate by both visual interpretation and activity detection. Therefore, 249 we further applied the height difference map to enhance the delineation accuracy. As the temperature 250 rises, the glaciers' tongue shape can be clearly discerned due to the significant lowering. The height 251 difference map is also a useful tool to discover surge activity and revise the delineation of advanced 252 glaciers. The edited glacial areas were then divided into individual glaciers according to the terrain 253 aspect, the glacier motion field, the height difference map and the other high-resolution optical 254 images (e.g. Map World images). 
Table 2 Images employed in this study

\begin{tabular}{|c|c|c|c|}
\hline Satellite Images & Acquisitiondate & $\begin{array}{c}\text { Item ID/Scene No.(TanDEM-X); } \\
\text { Path/Row (Landsat) }\end{array}$ & $\begin{array}{c}\text { Baseline }(\mathrm{m})(\text { TanDEM-X); } \\
\text { Cloud (Landsat) }\end{array}$ \\
\hline \multirow{27}{*}{$\begin{array}{c}\text { TanDEM-X/ } \\
\text { Coregistered Slant } \\
\text { Range Single Look } \\
\text { Complex }\end{array}$} & 4 Feb. 2012 & $1058642 / 6$ & 85.1 \\
\hline & 15 Feb. 2012 & $1058029 / 6$ & 85.8 \\
\hline & 26 Feb. 2012 & $1057411 / 7$ & 84.2 \\
\hline & 26 Feb. 2012 & $1057411 / 6$ & 84.1 \\
\hline & 26 Feb. 2012 & $1057411 / 5$ & 83.9 \\
\hline & 8 Mar. 2012 & $1056793 / 7$ & 82.3 \\
\hline & 8 Mar. 2012 & $1056793 / 6$ & 82.1 \\
\hline & 3 Mar. 2012 & $1056793 / 5$ & 81.8 \\
\hline & 19 Mar. 2012 & $1056168 / 6$ & 81.3 \\
\hline & 19 Jan. 2012 & $1059552 / 6$ & 85.3 \\
\hline & 30 Jan. 2012 & $1058915 / 5$ & 85.9 \\
\hline & 30 Jan. 2012 & $1058915 / 4$ & 85.8 \\
\hline & 10 Feb. 2012 & $1058301 / 5$ & 86.7 \\
\hline & 10 Feb. 2012 & $1058301 / 4$ & 86.6 \\
\hline & 21 Feb. 2012 & $1057700 / 5$ & 86.2 \\
\hline & 21 Feb. 2012 & $1057700 / 4$ & 86.0 \\
\hline & 3 Mar. 2012 & $1057074 / 4$ & 85.6 \\
\hline & 3 Mar. 2012 & $1057074 / 3$ & 85.4 \\
\hline & 25 Mar. 2012 & $1055825 / 4$ & 84.8 \\
\hline & 25 Mar. 2012 & $1055825 / 3$ & 84.6 \\
\hline & 20 Mar. 2012 & $1056103 / 5$ & 89.7 \\
\hline & 20 Mar. 2012 & $1056103 / 4$ & 89.7 \\
\hline & 9 Mar. 2012 & $1056733 / 5$ & 84.7 \\
\hline & 9 Mar. 2012 & $1056733 / 4$ & 84.7 \\
\hline & 27 Feb. 2012 & $1057350 / 5$ & 84.8 \\
\hline & 16 Feb. 2012 & $1057979 / 5$ & 84.7 \\
\hline & 5 Feb. 2012 & $1058586 / 5$ & 88.9 \\
\hline \multirow{16}{*}{ Landsat-7/ETM+ L1T } & 5 Aug. 2000 & $146 / 30$ & $4.1 \%$ \\
\hline & 5 Aug. 2000 & $146 / 31$ & $0.7 \%$ \\
\hline & 8 Aug. 2001 & $146 / 30$ & $4.6 \%$ \\
\hline & 8 Aug. 2001 & $146 / 31$ & $20.6 \%$ \\
\hline & 18 Aug. 2002 & $147 / 30$ & $0.2 \%$ \\
\hline & 18 Aug. 2002 & $147 / 31$ & $7.0 \%$ \\
\hline & 5 Oct. 2002 & $147 / 30$ & $0.2 \%$ \\
\hline & 5 Oct. 2002 & $147 / 31$ & $1.2 \%$ \\
\hline & 25 Aug. 2002 & $148 / 30$ & $5.6 \%$ \\
\hline & 25 Aug. 2002 & $148 / 31$ & $1.2 \%$ \\
\hline & 18 Sep. 1999 & $148 / 30$ & $2.7 \%$ \\
\hline & 18 Sep. 1999 & $148 / 31$ & $1.4 \%$ \\
\hline & 17 Aug. 1999 & $148 / 31$ & $7.2 \%$ \\
\hline & 24 Jul. 2002 & $148 / 31$ & $7.7 \%$ \\
\hline & 1 Jul. 2002 & $147 / 31$ & $21.0 \%$ \\
\hline & 17 Jul. 2002 & $147 / 31$ & $11.0 \%$ \\
\hline \multirow{6}{*}{ Landsat-8/OLI L1T } & 31 Aug. 2013 & $148 / 31$ & $2.4 \%$ \\
\hline & 25 Sep. 2013 & $147 / 30$ & $1.6 \%$ \\
\hline & 25 Sep. 2013 & $147 / 31$ & $23.9 \%$ \\
\hline & 12 Sep. 2014 & $147 / 31$ & $8.1 \%$ \\
\hline & 1 Aug. 2013 & $146 / 30$ & $0.2 \%$ \\
\hline & 1 Aug. 2013 & $146 / 31$ & $26.1 \%$ \\
\hline
\end{tabular}




\subsection{Glacier Thickness Change}

\subsubsection{Bias Correction}

Glacier thickness changes were measured by subtracting the SRTM DEM from the new DEM. Before differencing, the vertical reference of the new DEMs was converted from the WGS84 ellipsoid to the EGM96 geoid. The geolocation of the new DEM was determined by the transformation between the coordinates of the SRTM DEM and SAR images, and the transformation was built by the co-registration (image cross-correlation) between the SRTM DEM simulated SAR images and the real SAR images. Due to potential co-registration errors, horizontal shift might exist between the new DEM and the SRTM DEM. Since any small horizontal shift will induce significant DEM differencing errors in mountainous areas, checking the mismatches between the two DEMs is necessary. Basically, significant positive and negative height differences along the two sides of hill ridges are the indicators of horizontal shift. When performing DEM matching, we need to adopt an approach distinct from image cross-correlation. Kääb (2005) presented an analytical DEM matching method based on the strong correlation among raw height differences, horizontal shift, terrain aspect and local slope in non-glaciated areas (see Fig. 3a). For further details, refer to Kääb (2005), Nuth and Kääb (2011) and Paul et al. (2013). This method is suited to mountainous DEM differencing since the magnitude of the overall shift is sensitive to the terrain slopes. Furthermore, its iteration convergence speed is faster than other surface matching methods (Paul et al., 2013).

Previous studies have found systematic biases in height difference maps ( Berthier et al., 2007; Paul, 2008; Kääb, 2008; Nuth and Kääb, 2011; Pieczonka et al., 2013; Gardelle et al., 2013). Since the original image acquisition procedures are complicated, to determine a physical model for systematic bias is quite difficult. Generally, universal statistical approaches are employed to analyse and correct the systematic bias. More precisely, assuming that the distribution of the systematic bias shows no difference between the glaciated and non-glaciated areas, a global bias trend can be fitted on all the nonglacial height difference samples that are supposed to be zero (Berthier et al., 2007; Nuth and Kääb, 2011). The corrections are then realized by subtracting the trends from the new 
DEM. In this study, the different causes of systematic bias (planimetric position, altitude, terrain aspect, terrain slope and terrain curvature) were examined one by one in the 27 height difference maps. In each raw height difference map, a west-east planimetric trend was noted, which could not be relieved by co-registration correction. We found that the direction of the increasing trend was correlated with the direction of the CoSSC along-track baseline (vector). A positive or negative along-track baseline corresponds to a trend increasing towards the east or west, respectively. When the TDX or TSX satellite acts as the bistatic active satellite, the along-track baseline in the metadata file of the CoSSC is defined as positive or negative. Apparently, this kind of planimetric trend was induced by the residual baseline components. Following Pieczonka et al. (2013) a second-order polynomial surface fitting model was adopted to remove the planimetric position bias(see Fig. 3b).

Due to the slant-range image geometry, foreshortening is inevitable in mountainous areas. As a result, a terrain aspect related bias trend was detected in each raw height difference map. However, the coregistration correction could relieve this bias. A first-order Fourier series fitting model was adopted to correct the remaining terrain aspect related bias (see Fig. 3c). If the incidence angle of the TanDEM-X image is significantly different from that of the SRTM image, an obvious terrain slope related bias trend can be detected in raw map. A quadratic or cubic polynomial fitting model can be used to correct the slope-related bias (see Fig. 3d). According to Paul (2008), the pixel spacing discrepancy of two DEMs adopted for differencing can cause curvature-related bias. To achieve the height difference map with a pixel spacing of $15 \mathrm{~m}$, the SRTM DEM and the TanDEM-X images were oversampled and downsampled, respectively. Gardelle et al. (2012) proved that fitting the trend on the maximum curvature is an effective way to diminish this bias, and quadratic or cubic polynomial fitting was applied to correct the curvature-related bias (see Fig. 3e). Interestingly, unlike previous studies (Berthier et al., 2007; Kääb, 2008; Nuth and Kääb, 2011), no significant altituderelated bias was detected in the non-glaciated height differences in this study. The consistency of the slant-range image geometry of the TanDEM-X images and the SRTM DEM may explain this. 

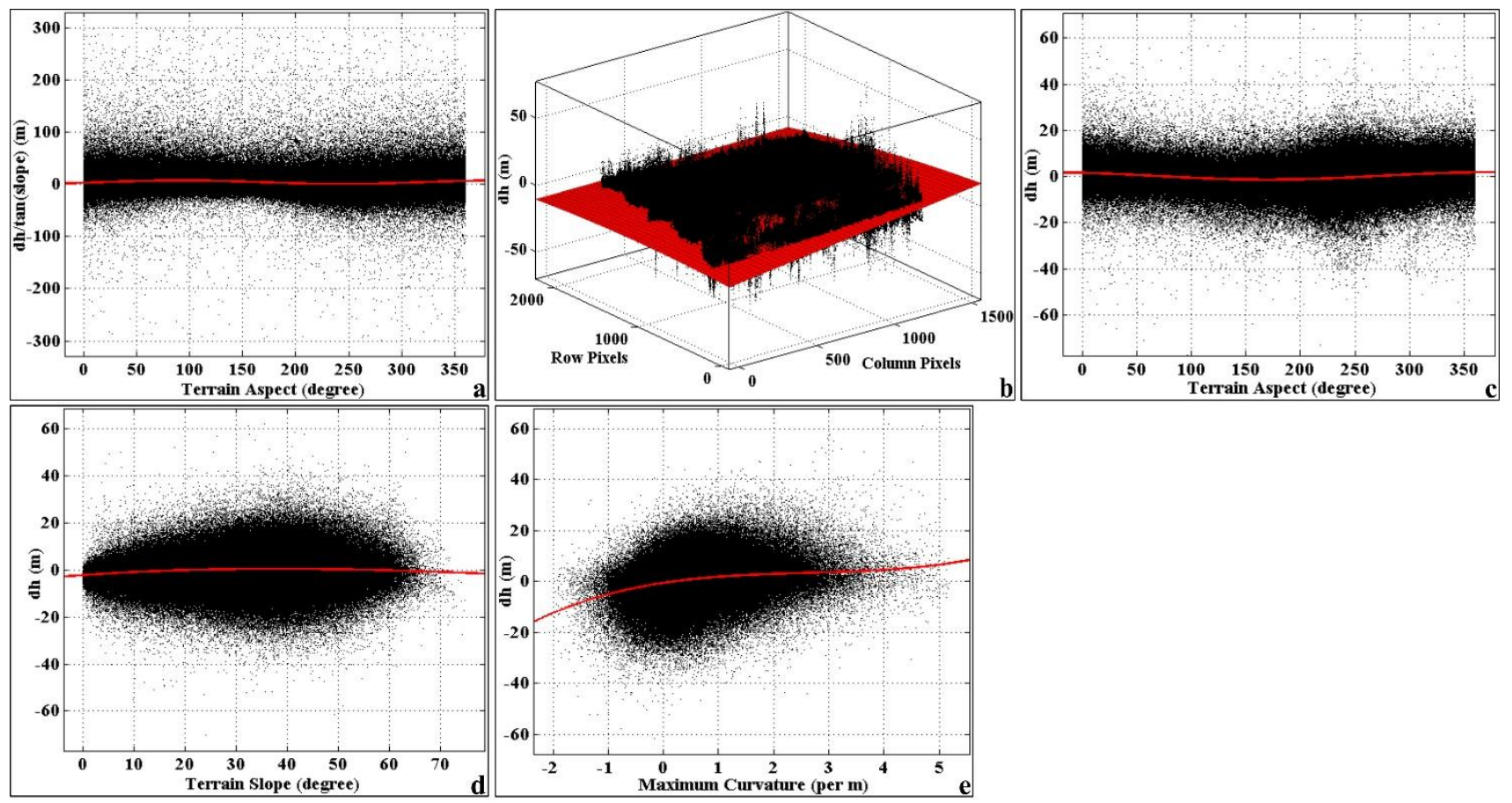

Fig. 3 Universal bias trends fitted for the nonglacial height differences in the area marked by red rectangle in Fig. 2.

(a) Scatter plot between the ratio of the nonglacial height difference over the tangent of the slope (dh/tan(slope)) and the terrain aspect (prior to co-registration correction). The red curve denotes the fitted model (cosine function). (b) Three-dimensional view of the scatterplot of the nonglacial height difference vs planimetric positions. The surface denotes the fitted trend using a quadratic surface polynomial. (c) Scatter plot of the nonglacial height difference vs terrain aspect. The red curve denotes the fitted trend using a first-order Fourier series. (d) Scatter plot of the nonglacial height difference vs terrain slope. The red curve denotes the fitted trend using a third-order polynomial. (e) Scatter plot of the nonglacial height difference vs maximum curvature. The red curve denotes the fitted trend using a third-order polynomial.

\subsubsection{Microwave Penetration Correction}

In addition to the above causes of bias, the intrinsic height difference resulting from the distinct surface penetration capabilities of C-band and X-band microwave should be considered (Berthier et al., 2006). With a longer wavelength, the C-band adopted by the SRTM is supposed to penetrate deeper into the ice/snow surface than the X-band adopted by the TanDEM-X mission. Gardelle et al. (2012, 2013) and Pieczonka et al. (2013) estimated the C-band penetration-related bias by differencing the SRTM-C (C-band SRTM) and SRTM-X (X-band SRTM) DEMs over the glaciated area. Distributed by the DLR, the SRTM-X DEM was acquired simultaneously with the SRTM-C 
DEM. The SRTM-X and SRTM-C DEMs were also coregistered before differencing, and bias

corrections were applied to the height difference map. We then extracted the height difference over the glaciated areas. The final average C-band penetration depth of the entire CTS was determined to be $2.7 \pm 0.5 \mathrm{~m}$, and $1.9 \pm 0.5 \mathrm{~m}, 3.1 \pm 0.5 \mathrm{~m}$ and $2.2 \pm 0.5 \mathrm{~m}$ for ETASAKEK, HHKTXT and BHT, respectively. Previously, Kääb et al. (2012) and Gardelle et al. (2013) reported that the SRTM Cband penetration depths in the Karakoram, East Nepal-Bhutan and Bhutan areas were $2.4 \mathrm{~m}, 2.5 \mathrm{~m}$ and $2.4 \mathrm{~m}$, respectively. It is reasonable that the CTS has a comparable SRTM C-band penetration depth (2.7 m). In addition, Pieczonka and Bolch (2015) obtained an SRTM C-band penetration depth of $2.2 \mathrm{~m}$ for the CTS by extrapolating the robust linear regression on the average differences between the 2003-2009 ICESat/GLAS GLA14 elevations and the C-band SRTM. We took the discrepancy between the two results as the measurement error of the C-band penetration depth, i.e., $0.5 \mathrm{~m}$. When calculating the average glacier thickness change of a sub-region, we subtracted the average penetration depth from the average glacial height difference. To some extent, the distribution of $\mathrm{C} / \mathrm{X}$ band height differences was correlated with the glacier sections. From the foot to the head, more pure ice is exposed as the altitude increases, and the surface dry snow/firn becomes increasingly thick. Correspondingly, the penetration depth of the C-band increases and reaches its maximum in the highest firn base. Before penetration depth correction, almost all the accumulation zones of big glaciers in the high mountains seem obviously heightened. In order to present a more accurate glacier thickness change map, we corrected the penetration depth of each point according to the local altitude (Gardelle et al., 2013). Since the landforms can also affect the preservation of snow/firn, penetration correction based on altitude may result in errors. To minimize such errors, we grouped the glaciers in terms of their location, size, hypsometry and debris coverage. For each kind of glacier, the polynomial fitting was performed separately.

\subsubsection{Average Glacier Thickness Change Calculation}

Due to the extremely rugged terrain, InSAR will be faced with decorrelation problems induced by the foreshortening, layover and shadows. In order to obtain a full coverage, combining the images 
acquired from different tracks (ascending/descending or adjacent) and interpolating the thickness

change map are usually adopted. However, in this study, only the ascending TanDEM-X images met the demand of temporal consistency. We excluded the raw height differences with an absolute value larger than $100 \mathrm{~m}$. In addition, a coherence threshold of 0.3 was set for the TanDEM-X interferograms. Consequently, the surrounding areas of high horns (pointed pyramidal peaks created by three or more arêtes) and arêtes (narrow crests) are often missing in the height difference map. However, the major height difference voids in the Intermontane Basin and Halk Tawu were due to the data voids of the original SRTM DEM. We adopted a glaciological method to calculate the representative thickness changes (Kääb, 2008). Note that the surge and non-surge glaciers were treated separately. In each altitude range, the points with thickness change magnitudes of three standard deviations larger than the mean were excluded as outliers. On the headwalls, the snow/ice thickness changes should be slight. As shown in Figs. 4-6, the observed height changes in the joint parts between firn bases and the steep sides of horns/arêtes were negligible. In this case, the missing thickness changes on the sides of the high horns and arêtes (with a slope larger than $23^{\circ}$ ) were assumed to be zeros. As for the moderate glacier beds where thickness change observations were missing due to the SAR signal decorrelation or the original data voids in the SRTM DEM, we assigned them the average thickness change of the altitude interval they were located in (Gardelle et al., 2013). Despite the missing observations in some glacier beds, for the region-wide estimation, the number of effective observations in each altitude range was sufficient. Interpolation can result in large uncertainties, so was not performed. In order to facilitate interpretation of the results, all the height difference maps in this paper share the same colour bar $(-80 \sim 80 \mathrm{~m})$.

\subsubsection{Snowline Calculation}

The accumulation and ablation areas are divided by equilibrium line which cannot be simply detected on the surface. However, the snowline can be considered as the approximation of equilibrium line. We therefore extract the snowline for each sub-region to differentiate the glacier thickness changes in the accumulation and ablation zones. Firstly, firn/snow was discriminated from 
ice by setting a threshold of 200 on the $0-255$ stretched DN ratio (TM4×TM2)/TM5 of Landsat images acquired at the end of ablation season (Kääb et al., 2012). We then manually digitized regular snowlines (curves) from the discrimination result (Gardelle et al., 2013). For each sub-region, the glaciers were grouped into four ranks according to their sizes. The glaciers for snowline delineation were evenly sampled with regard to location, altitude and aspect. In total, the snowlines for 354 glaciers (covering an area of $4537 \mathrm{~km}^{2}$ ) were delineated. A representative snowline was determined for each sub-region using an area-weighted average. In the CTS (excluding BHT), Pieczonka and Bolch (2015) computed the regional snowline from the values specified in the Glacier Inventory of the Union of Soviet Socialist Republics (1973) as $4300 \mathrm{~m}$ a.s.1., and ours is $4231 \mathrm{~m}$ a.s.1. Specifically, for the large glaciers including Petrova, Dschamansu, Kaindy (Akshiirak), Northern Inylchek, Southern Inylchek, Carind, Tuomuer, Koxkar and Keqikete Liekesu, the area-weighted average snowline listed in Pieczonka and Bolch (2015) is $4398 \mathrm{~m}$, and ours is $4376 \mathrm{~m}$ a.s.l., so the differences are small.

\subsection{Uncertainty}

We needed to evaluate the uncertainty of the results before interpreting them. In the study, four sources of uncertainty for the glacier thickness change were taken into account. The first was the height difference measurement error. In theory, the height difference of stable regions should be zero. Assuming that the glacial and nonglacial height differences are common and share the same measurement precision, we can take the standard deviation (STD) of the height difference over the stable regions to evaluate the height difference measurement error. However, as proved by Höhle and Höhle (2009), the height differences between two mountainous DEMs derived by remote sensing techniques inevitably contain a considerable number of outliers, and therefore the normal STD is prone to being overestimated. According to the suggestion of Höhle and Höhle (2009), we used the normalized median absolute deviation (NMAD) to replace the STD. In essence, the NMAD is a more robust estimator of the STD when a considerable number of outliers exist. It can be computed as follows: 
where $\Delta h_{i}$ is the nonglacial height difference, and median $_{\Delta h}$ is the median of the nonglacial height difference samples. The NMAD is proportional to the median of the absolute difference between $\Delta h_{i}$ and median $_{\Delta h}$. In order to be conservative, we only counted the nonglacial samples above the lower altitude limit of the glacier distribution (2675 m a.s.1.). The final NMAD of the entire CTS nonglacial height difference above $2675 \mathrm{~m}$ a.s.l. was $2.47 \mathrm{~m}$, and $1.86 \mathrm{~m}, 2.74 \mathrm{~m}$ and $3.04 \mathrm{~m}$ for ETASAKEK, HHKTXT and BHT, respectively. The second source of uncertainty was the C-band penetration correction error, i.e., $0.5 \mathrm{~m}$. RGI 5.0 excluded thin ice on headwalls and derived a glacier area smaller than those measured according to the GLIMS (Global Land Ice Measurements from Space initiative) guidelines in High Mountain Asia (Arendt et al., 2015). As mentioned in Section 3.3.3, the headwalls should see only slight glacier thickness change, even though they are considered as parts of the glacier in this study. With regard to the glacier delineation in RGI 5.0, we considered the difference in the average thickness change caused by excluding the samples on headwalls as a further source of uncertainty. Furthermore, the uncertainty caused by glacier outline delineation error was also computed. According to the zoom level of the Landsat-7 ETM+ multispectral-panchromatic fused images, we assumed a delineation uncertainty of one image pixel, i.e., $15 \mathrm{~m}$ (Hagg et al., 2013). This uncertainty corresponds to a glacier area deviation of $\pm 7.3 \%, \pm 9.6 \%, \pm 5.8 \%$ and $\pm 10.0 \%$ for the CTS, ETASAKEK, HHKTXT and BHT, respectively. By setting a $15 \mathrm{~m}$ buffer zone along the glacier outlines, we derived the glacier thickness change rate with a difference of only $\pm 0.004 \mathrm{~m} / \mathrm{a}$ relative to the original one. The above four sources of uncertainty were deemed independent, and the

424 final region-wide glacier thickness change rate uncertainty was computed based on the standard error 425 propagation principle. For the CTS, ETASAKEK, HHKTXT and BHT, the values were $\pm 0.22 \mathrm{~m} / \mathrm{a}$, 426 $\pm 0.17 \mathrm{~m} / \mathrm{a}, \pm 0.24 \mathrm{~m} / \mathrm{a}$ and $\pm 0.26 \mathrm{~m} / \mathrm{a}$, respectively. 


\section{Results}

\subsection{Overall Thickness Changes}

In total, $7239.8 \pm 527.2 \mathrm{~km}^{2}$ of glaciers were delineated in the CTS, and $78.9 \%$ of the glacier surface was covered by effective height difference measurements. Except for the surge glaciers, most glaciers in the CTS have shown significant thinning in their ablation zones from 2000 to 2012. The average thinning rate was $-0.24 \pm 0.22 \mathrm{~m} / \mathrm{a}$. Strong thinning $(-4.80 \pm 2.64 \mathrm{~m})$ was observed in the glacier ablation zones $\left(2845.2 \pm 207.2 \mathrm{~km}^{2}\right)$ and moderate $(-1.56 \pm 2.64 \mathrm{~m})$ thinning in the accumulation zones $\left(4394.6 \pm 320.0 \mathrm{~km}^{2}\right)$. Tables 3 and 4 show the glacier thickness changes and the vital indexes for illustrating the change features (such as the snowline, the debris coverage and the average glacier bed altitude). Glaciers without specific names were given the glacier inventory ID.

\subsection{Sub-region Thickness Changes}

\subsubsection{East Terskey-Alatoo, Suek, Akshiirak, Koilu and East Kakshaal}

In ETASAKEK (see Fig. 4), the regional glacier thickness change rate was $-0.26 \pm 0.17 \mathrm{~m} / \mathrm{a}$, and for the five independent mountain ranges, i.e., Suek, East Terskey-Alatoo, Arshiirak, Koilu and East Kakshaal, the values range from $-0.37 \pm 0.16 \mathrm{~m} / \mathrm{a}$ to $-0.17 \pm 0.20 \mathrm{~m} / \mathrm{a}$ (see Table 3 ). The Suek mountain range is the shortest. Glaciers developed here have smallest sizes, and the regional glacier thinning rate was the highest $(-0.37 \pm 0.16 \mathrm{~m} / \mathrm{a})$. The Arshiirak mountain range saw the most notable glacier decline; however, the glaciers developed here are the largest, and the accumulation zones thinned at tiny rates $(-0.01 \pm 0.17 \mathrm{~m} / \mathrm{a})$. Its regional glacier thinning rate $(-0.23 \pm 0.17 \mathrm{~m} / \mathrm{a})$ was below the average value of ETASAKEK. Although the glaciers in the Koilu mountain range have relatively small sizes, the average altitude of their beds (4389 $\mathrm{m}$ a.s.1.) was the highest and the average thinning rate of their ablation zones was the lowest $(-0.37 \pm 0.16 \mathrm{~m} / \mathrm{a})$. Meanwhile, several surge glaciers in this area gained a significant amount of mass in their upper reaches. Hence, the Koilu mountain range saw the lowest regional glacier thinning rate $(-0.17 \pm 0.20 \mathrm{~m} / \mathrm{a})$. Four prominent glaciers in ETASAKEK, i.e., Kopakovsky, Petrova, Dschamansu and Kaindy (see Fig. 4), 
452 were found to thin at rates ranging from $-0.23 \pm 0.16 \mathrm{~m} / \mathrm{a}$ to $-0.34 \pm 0.17 \mathrm{~m} / \mathrm{a}$ (see Table 4 ). Drastic

453 thinning of up to $-82 \mathrm{~m}$ and $-89 \mathrm{~m}$ was observed at the Kopakovsky and Petrova glaciers' distal

454 parts (in small local parts, see Figs. 3 and 7), respectively.

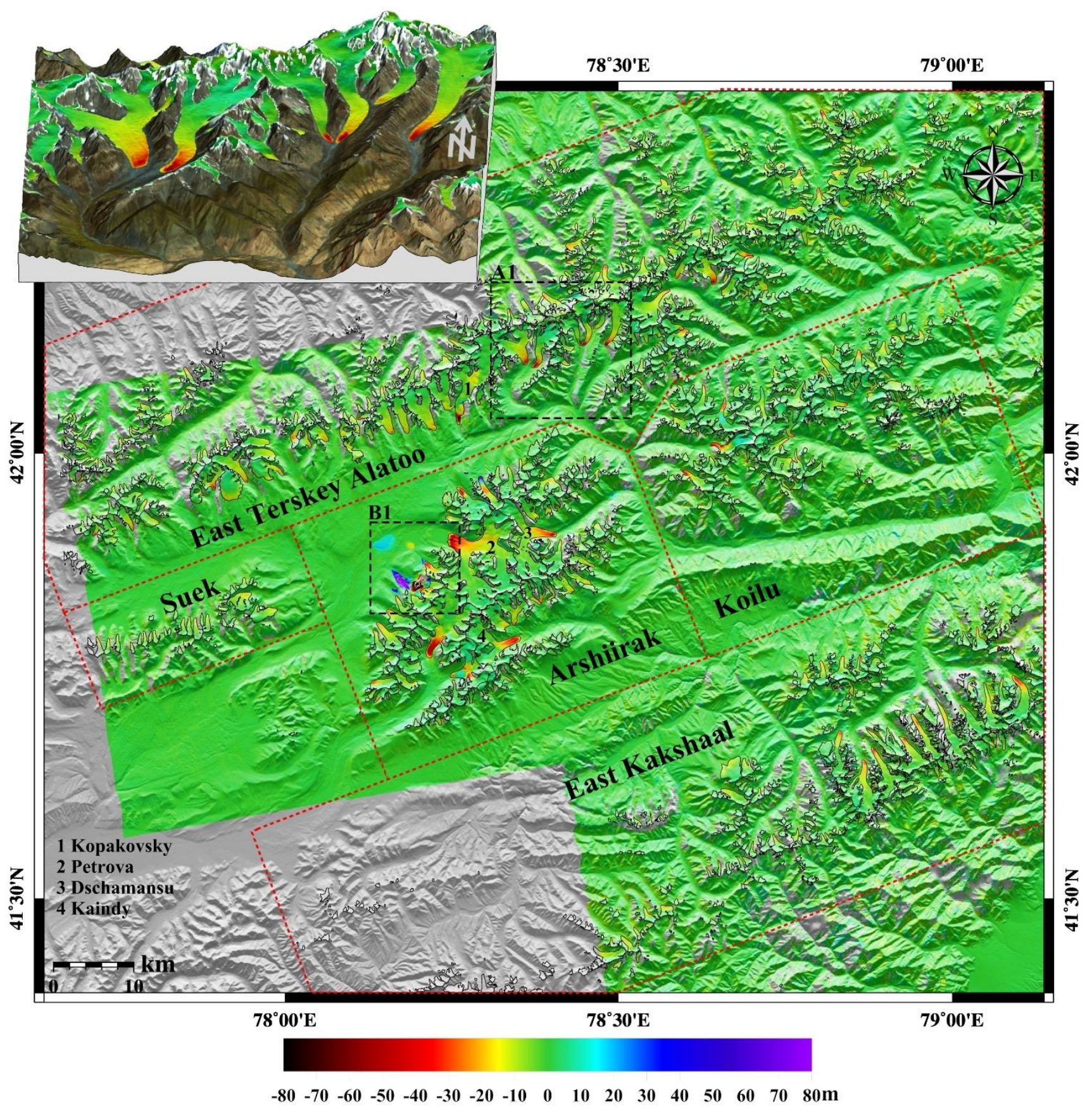

Fig. 4. Surface height changes in ETASAKEK during 2000-2012. The solid black curves denote the glacier

457 outlines. Numbers 1-4 denote the different glaciers, with the names given in the lower left of the figure. Sub-

458 regions are marked by the dotted red lines and black text. The inset panel is a 3D zoom of the glacier thickness

459 change within dashed black rectangle A1. 
HHKTXT had a regional glacier thinning rate of $-0.21 \pm 0.24 \mathrm{~m} / \mathrm{a}$. Among its three sub-regions

(see Fig. 5), the Northern Slope has the lowest altitude. Glaciers developed there are relatively small, and most of their surfaces are exposed. Its regional glacier thinning rate was the highest $(-0.34 \pm$

$0.24 \mathrm{~m} / \mathrm{a}$ ). The Intermontane Basin is so high in elevation that it gives birth to a number of huge glaciers, six of which have an area of over $100 \mathrm{~km}^{2}$ (Northern and Southern Inylchek, Carind, Tuge

Biliqi, Wu Cuer and Muzart). These huge glaciers cover a large altitude range (2675 6500 m a.s.1.).

Average thinning rate was significant in the ablation zone $(-0.40 \pm 0.20 \mathrm{~m} / \mathrm{a})$. Although thickening of up to $10 \mathrm{~m}$ was observed in the firn bases of huge glaciers, the Northern Inylchek and Carind glacier trunks, as well as one major tributary of the Southern Inylchek glacier, surged in the observation period. Therefore, the average accumulation thickness change rate was still negative $(-0.06 \pm 0.26 \mathrm{~m} / \mathrm{a})$. The Southern Slope is also extremely high in elevation. Relative to the huge glaciers (say over $50 \mathrm{~km}^{2}$ ) in the Intermontane Basin, those in the Southern Slope have smaller sizes but higher proportions of debris coverage, and they basically experienced less intensive thinning in their ablation zones (see Table 4). The regional average glacier thinning rate in the Southern Slope $(-0.17 \pm 0.24 \mathrm{~m} / \mathrm{a})$ was the lowest. However, due to the common surges, the average thinning rate in the accumulation zones $(-0.18 \pm 0.24 \mathrm{~m} / \mathrm{a})$ was even higher than that in the ablation zones $(-0.15 \pm$ $0.23 \mathrm{~m} / \mathrm{a}$ ). The 17 prominent glaciers in HHKTXT (including Kara Cumai, Seminova, Musktov, 478 Archur Leter, CN5X046G0048 and the 12 glaciers mentioned above) were found to thin at rates 479 ranging from $-0.10 \pm 0.27 \mathrm{~m} / \mathrm{a}$ to $-0.33 \pm 0.23 \mathrm{~m} / \mathrm{a}$. The greatest lowering $(-82 \mathrm{~m})$ was found on the 480 drainage outlet of the Southern Inylchek glacier (in small local parts, see Fig. 5). 


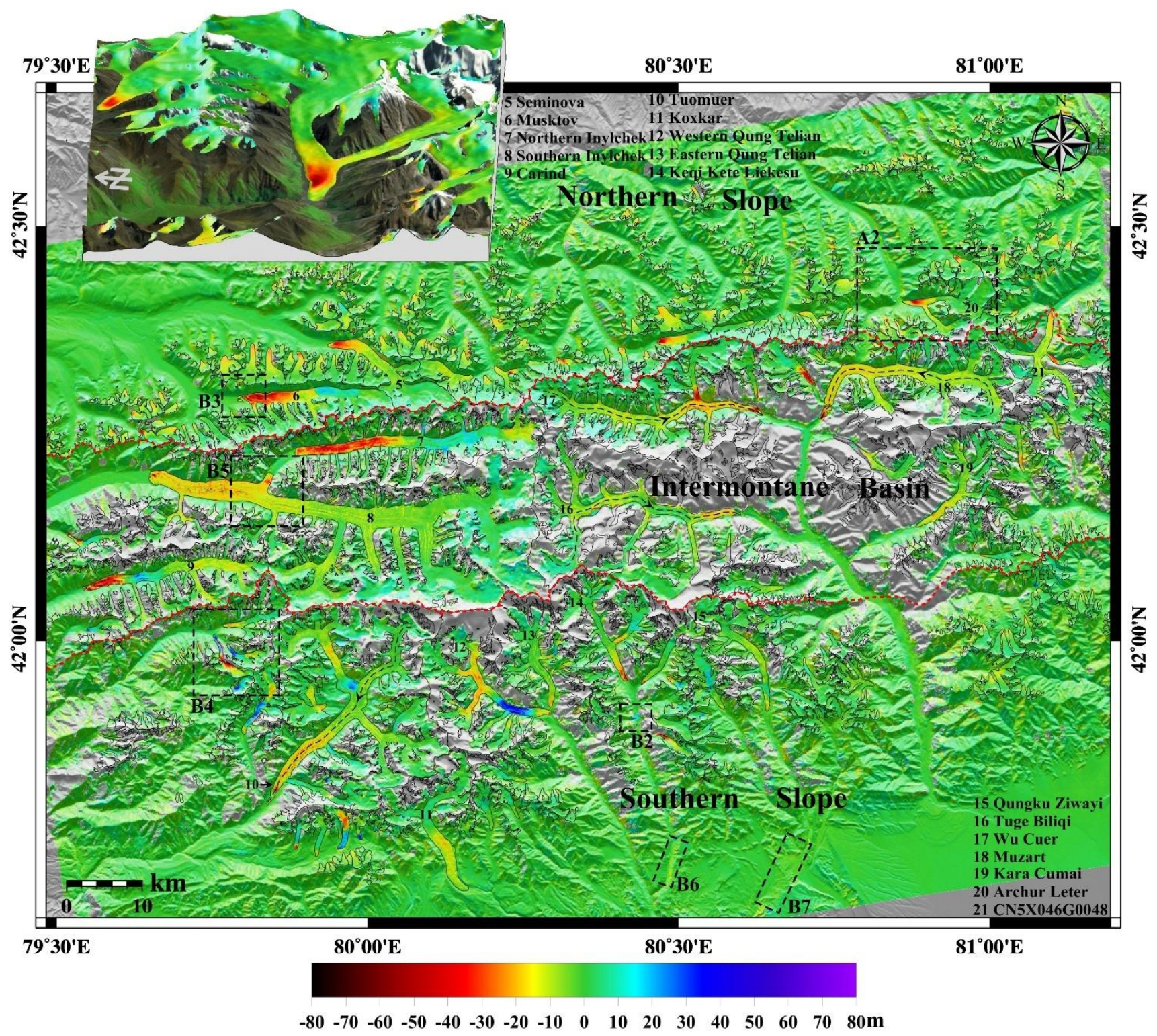

Fig. 5. Surface height changes in HHKTXT during 2000-2012. The solid black curves denote the glacier outlines.

Numbers 5-21 denote the different glaciers, with the names given in the upper middle and the lower right of the

figure. The dashed black lines in the glacier trunks mark the locations of the profiles in Fig. 10. Sub-regions are marked by the dotted red lines and the black text. The inset panel is a 3D zoom of the glacier thickness change within dashed black rectangle A2.

\subsubsection{Biyeek and Halk Tawu}

In BHT, although the glacier distribution altitude range is similar to that in ETASAKEK, the average glacier bed altitude is lower (4040 m vs. $4280 \mathrm{~m}$ a.s.1.). The regional glacier thinning rate was the highest $(-0.29 \pm 0.26 \mathrm{~m} / \mathrm{a})$ among the three first-level sub-regions. Significant thinning rate was observed not only in the ablation zones $(-0.44 \pm 0.26 \mathrm{~m} / \mathrm{a})$ but also in the accumulation zones 
$492(-0.21 \pm 0.26 \mathrm{~m} / \mathrm{a})$. A number of empty glacier beds were found in BHT, indicating that strong 493 glacier shrinkage had occurred in BHT before 2000. BHT consists of two long mountain ranges, 494 Biyeek and Halk Tawu. The Biyeek mountain range in the north is much lower than the Halk Tawu 495 mountain range (3840 m vs. $4075 \mathrm{~m}$ a.s.l.). The glacier area we delineated in the Biyeek mountain 496 range took up only $14.7 \%$ of BHT. Thinning rates in both the ablation zones $(-0.51 \pm 0.26 \mathrm{~m} / \mathrm{a})$ and 497 accumulation zones $(-0.23 \pm 0.26 \mathrm{~m} / \mathrm{a})$ of glaciers in the Biyeek mountain range were higher than in 498 the Halk Tawu mountain range $(-0.43 \pm 0.26 \mathrm{~m} / \mathrm{a}$ and $-0.21 \pm 0.26 \mathrm{~m} / \mathrm{a})$. Two prominent glaciers in 499 the BHT, CN5X046E0089 and CN5X045D0025, were found to thin at rates of $-0.19 \pm 0.27 \mathrm{~m} / \mathrm{a}$ and $500-0.16 \pm 0.26 \mathrm{~m} / \mathrm{a}$, respectively.

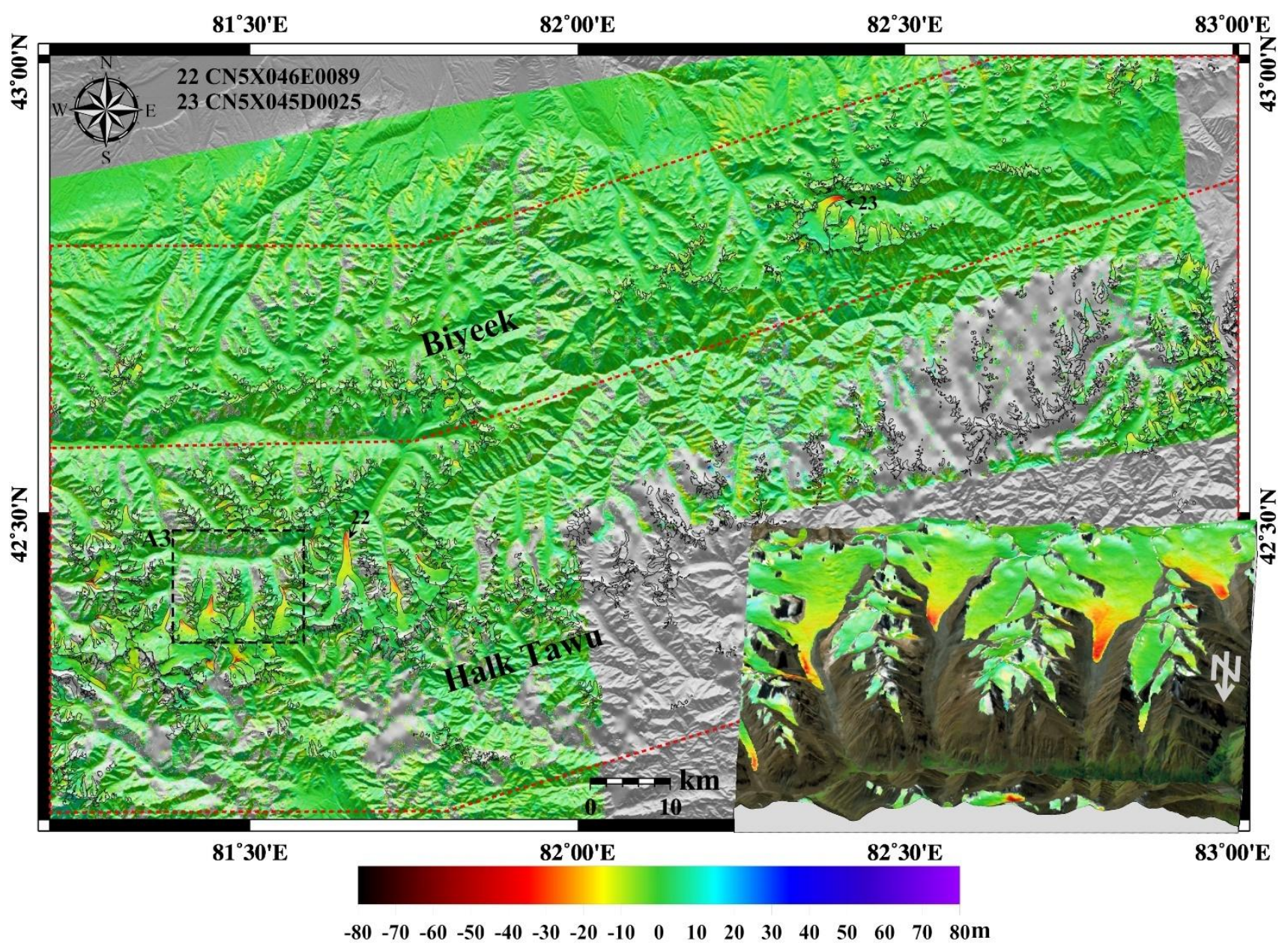

502 Fig. 6. Surface height changes inBHT during 2000-2012. The solid black curves denote the glacier outlines.

503 Numbers 22 and 23 denote the different glaciers, with the names given in the upper left of the figure. Sub-regions 504 are marked by the dotted red lines and black text. The inset panel is a 3D view of glacier thickness change in 505 dashed black rectangle A3. 
Table 3 Glacier thickness change in the CTS during 2000-2012

\begin{tabular}{|c|c|c|c|c|c|c|c|c|c|c|c|}
\hline \multirow{2}{*}{ Massif } & \multicolumn{5}{|c|}{ ETASAKEK } & \multicolumn{3}{|c|}{ HHKTXT } & \multicolumn{2}{|c|}{ BHT } & \multirow{2}{*}{$\begin{array}{r}\text { Central } \\
\text { Tien Shan }\end{array}$} \\
\hline & $\begin{array}{c}\text { East Terskey- } \\
\text { Alatoo }\end{array}$ & Arshiirak & Koilu & Suek & $\begin{array}{c}\text { East } \\
\text { Kakshaal }\end{array}$ & $\begin{array}{l}\text { Northern } \\
\text { Slope }\end{array}$ & $\begin{array}{l}\text { Intermont- } \\
\text { ane Basin }\end{array}$ & $\begin{array}{c}\text { Southern } \\
\text { Slope }\end{array}$ & Biyeek & Halk Tawu & \\
\hline \multirow{2}{*}{$\begin{array}{l}\text { Snowline } \\
\text { (m a.s.l.) }\end{array}$} & \multicolumn{5}{|c|}{4242} & \multicolumn{3}{|c|}{4227} & \multicolumn{2}{|c|}{3918} & \\
\hline & 4144 & 4328 & 4298 & 4229 & 4301 & 3967 & 4292 & 4278 & 3794 & 3939 & \\
\hline \multirow{2}{*}{ Accumulation area ratio } & \multicolumn{5}{|c|}{$56.1 \%$} & \multicolumn{3}{|c|}{$60.3 \%$} & \multicolumn{2}{|c|}{$68.1 \%$} & \\
\hline & $51.1 \%$ & $56.4 \%$ & $60.8 \%$ & $48.9 \%$ & $63.2 \%$ & $56.8 \%$ & $60.2 \%$ & $62.3 \%$ & $59.1 \%$ & $69.6 \%$ & $00.1,10$ \\
\hline \multirow{2}{*}{$\begin{array}{l}\text { Average glacier bed altitude } \\
\text { (m a.s.l.) }\end{array}$} & \multicolumn{5}{|c|}{4280} & \multicolumn{3}{|c|}{4383} & \multicolumn{2}{|c|}{4040} & \\
\hline & 4146 & 4357 & 4389 & 4227 & 4380 & 4049 & 4467 & 4448 & 3840 & 4075 & 4304 \\
\hline \multirow{2}{*}{ Total glacier area $\left(\mathrm{km}^{2}\right)$} & \multicolumn{5}{|c|}{$1494.5 \pm 144.1$} & \multicolumn{3}{|c|}{$4519.1 \pm 261.0$} & \multicolumn{2}{|c|}{$1226.2 \pm 122.1$} & 7239.8 \\
\hline & 594.9 & 360.4 & 200.0 & 32.4 & 306.8 & 845.8 & 2208.7 & 1464.6 & 179.9 & 1046.2 & \pm 527.2 \\
\hline \multirow{2}{*}{ Debris coverage } & \multicolumn{5}{|c|}{$5.6 \%$} & \multicolumn{3}{|c|}{$14.6 \%$} & \multicolumn{2}{|c|}{$6.3 \%$} & \\
\hline & $6.2 \%$ & $4.4 \%$ & $5.6 \%$ & $2.9 \%$ & $6.3 \%$ & $9.4 \%$ & $15.3 \%$ & $16.5 \%$ & $4.8 \%$ & $6.6 \%$ & $11.3 \%$ \\
\hline \multirow{2}{*}{$\begin{array}{c}\text { Thickness change } \\
\text { measurement coverage }\end{array}$} & \multicolumn{5}{|c|}{$91.0 \%$} & \multicolumn{3}{|c|}{$76.5 \%$} & \multicolumn{2}{|c|}{$72.7 \%$} & \\
\hline & $91.8 \%$ & $94.3 \%$ & $97.4 \%$ & $91.0 \%$ & $81.4 \%$ & $95.9 \%$ & $68.3 \%$ & $77.8 \%$ & $97.6 \%$ & $68.5 \%$ & $18.9 \%$ \\
\hline Accumulation zone & \multicolumn{5}{|c|}{$-0.08 \pm 0.17$} & \multicolumn{3}{|c|}{$-0.12 \pm 0.24$} & \multicolumn{2}{|c|}{$-0.21 \pm 0.26$} & \multirow{2}{*}{$-0.13 \pm 0.22$} \\
\hline thickness change rate $(\mathrm{m} / \mathrm{a})$ & $-0.12 \pm 0.18$ & $-0.01 \pm 0.17$ & $-0.04 \pm 0.22$ & $-0.18 \pm 0.16$ & $-0.09 \pm 0.18$ & $-0.18 \pm 0.24$ & $-0.06 \pm 0.26$ & $-0.18 \pm 0.24$ & $-0.23 \pm 0.26$ & $-0.21 \pm 0.26$ & \\
\hline Ablation zone & & & $-0.50 \pm 0.17$ & & & & $-0.35 \pm 0.24$ & & -0.44 & $4 \pm 0.26$ & \\
\hline thickness change rate $(\mathrm{m} / \mathrm{a})$ & $-0.53 \pm 0.17$ & $-0.52 \pm 0.17$ & $-0.37 \pm 0.16$ & $-0.54 \pm 0.16$ & $-0.48 \pm 0.18$ & $-0.55 \pm 0.25$ & $-0.40 \pm 0.24$ & $-0.15 \pm 0.23$ & $-0.51 \pm 0.26$ & $-0.43 \pm 0.26$ & \\
\hline Average thickness & & & $-0.26 \pm 0.17$ & & & & $-0.21 \pm 0.24$ & & -0.29 & \pm 0.26 & \\
\hline change (m/a) & $-0.32 \pm 0.17$ & $-0.23 \pm 0.17$ & $-0.17 \pm 0.20$ & $-0.37 \pm 0.16$ & $-0.23 \pm 0.18$ & $-0.34 \pm 0.24$ & $-0.20 \pm 0.25$ & $-0.17 \pm 0.24$ & $-0.35 \pm 0.26$ & $-0.28 \pm 0.26$ & \\
\hline
\end{tabular}
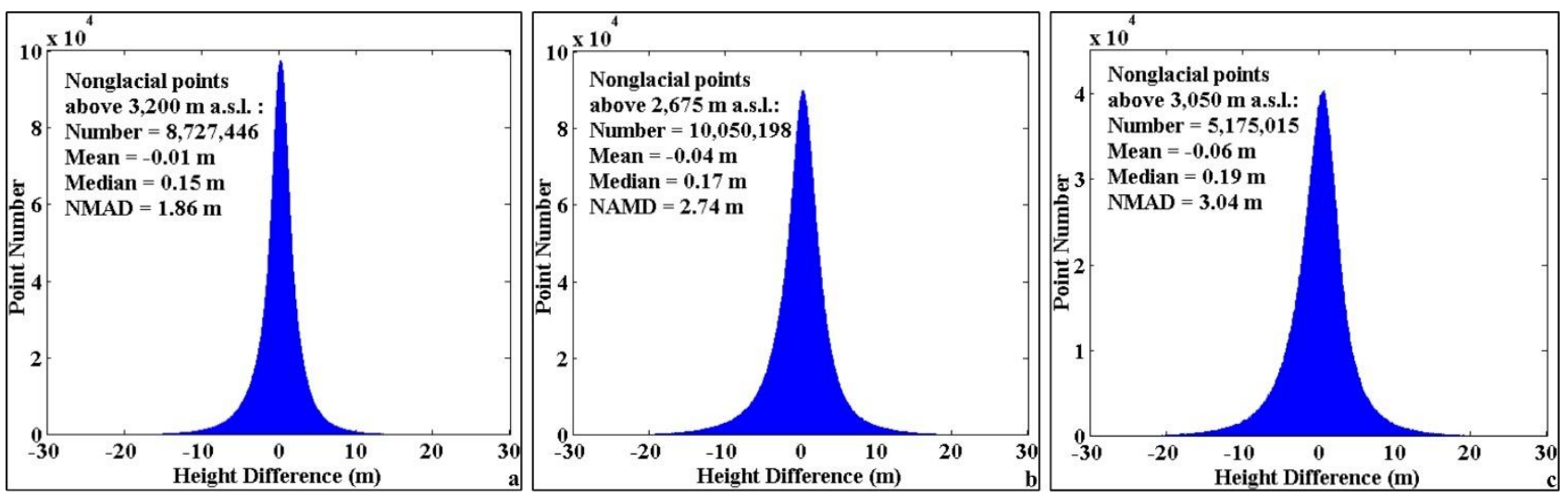

Fig. 7. Statistics nonglacial height differences in three first-level sub-regions. Figures (a)-(c) represent

ETASAKEK (Fig. 4), HHKTXT (Fig. 5) and BHT (Fig. 6), respectively. 


\section{Discussions}

\subsection{Patterns of Surface Height Changes}

Ground surface height varies due to natural phenomena. If the specific natural phenomena that caused the height changes could be revealed, our results would be more reasonable and convincing. Some regions with typical height change patterns are selected for illustration. Based on the features of these height changes and optical images, we identified the specific natural phenomena to which the height changes could be attributed. Note that the optical images were acquired in the same season, making the view comparison more reasonable.

\subsubsection{Land Change Activities and Normal Glacier Changes}

The largest height changes in this study were detected in the west of the Arshiirak mountain range (see rectangle B1 in Fig. 4). Seen from Fig. 8, height changes E were caused by normal glacier decline, as they become increasingly negative towards the glacier terminus (vary continuously) and resemble the shape of the glacier outline. Height changes A were caused by land reclamation. The area between the lowered and heightened regions remained unchanged, indicating that the earth was artificially transferred from the lowered region to the heightened region. The largest lowering D and heightening $\mathrm{C}$ were caused by mining and piling of mine waste, respectively. The Kumtor Gold Mine operates at this location (David et al., 2015). In the place where height changes B occurred, a new mine waste pile emerged after 17 August 1999. Note that, in Fig. 8b, the pile front in the extending direction is steep, indicating that the pile was flowing forward naturally on 24 July 2002 . Hence, the slide of the mine waste pile caused height changes B. In addition, we observed some slight lowering on the steep river sides (see rectangle B6 in Fig. 5) and in the barren river catchment (see rectangle B7 in Fig. 5), respectively. To a large extent, the soil erosion during rainy season was the cause of these changes. 


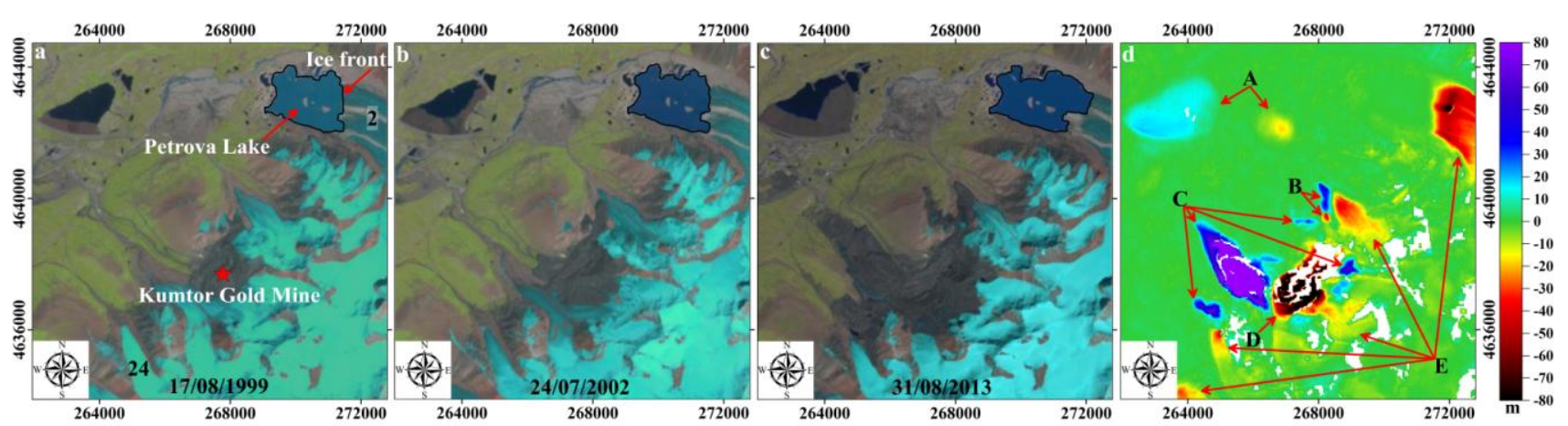

Fig. 8 Landsat images (a)-(c) and surface height changes (d) of the area marked by rectangle B1 in Fig. 4. Images

(a)-(c) were acquired on 17 August 1999, 24 July 2002 and 31 August 2013, respectively. Numbers 2 and 24 represent the Petrova and Sary-Tor glaciers, respectively. The area outlined by the black line is Lake Petrova.

Projection coordinates (UTM 44N, unit: m) are applied. Note that the real height change magnitudes caused by mining and the piling of mine waste reach $205 \mathrm{~m}$. However, in order to be consistent with the other height change maps, the range of the colour bar is confined to $-80 \sim 80 \mathrm{~m}$.

\subsubsection{Dead Ice Decline}

Dead ice is the isolated ice defined in contrast to the living ice, i.e., the glacier body (Ren, 1990). If the decline in a lower part of a glacier is too acute, the glacier snout can be 'cut off' from the main body. Since the replenishment from the higher part is ceased, the remaining ice body becomes increasingly thin and stagnant. However, if the remaining ice body is large enough, it will still move slowly, and will take a long time to disappear. Furthermore, the original supraglacial debris will still be attached to the ice body. Due to the underlying ablation, the glacial thermal karsts will remain. Therefore, the cover of the dead ice appears similar to that of the glacier snout. Dead ice usually emerges ahead of a surge glacier which is in the quiescent phase. According to Su et al. (1985) and Liu et al. (1998), the Musktov glacier (glacier No. 6) surged $4.5 \mathrm{~km}$ between 1956 and 1957. Ahead of the Musktov glacier, we observed two small lowered areas. Although the lowering was much less than that of the main glacier body, the two small areas together with the main glacier body formed a typical glacier tongue which has advanced. Therefore, we deduced that the lowering of the two small areas was caused by the decline of the dead ice that emerged during the earlier quiescent phase. 
shared similar debris cover to the Musktov glacier's tongue. The sharp contrast in appearance between the supraglacial debris and the proglacial moraine/sediment allowed these two areas to be easily distinguished. However, in the image acquired on 25 September 2013, the debris over these two small areas had almost disappeared. Such changes indicated these two areas used to be underlain by dead ice, but they were mostly ablated during the observation period, which is consistent with the above deduction. To the best of our knowledge, the decline in the dead ice was first revealed based on the spaceborne optical view and the InSAR height change map.

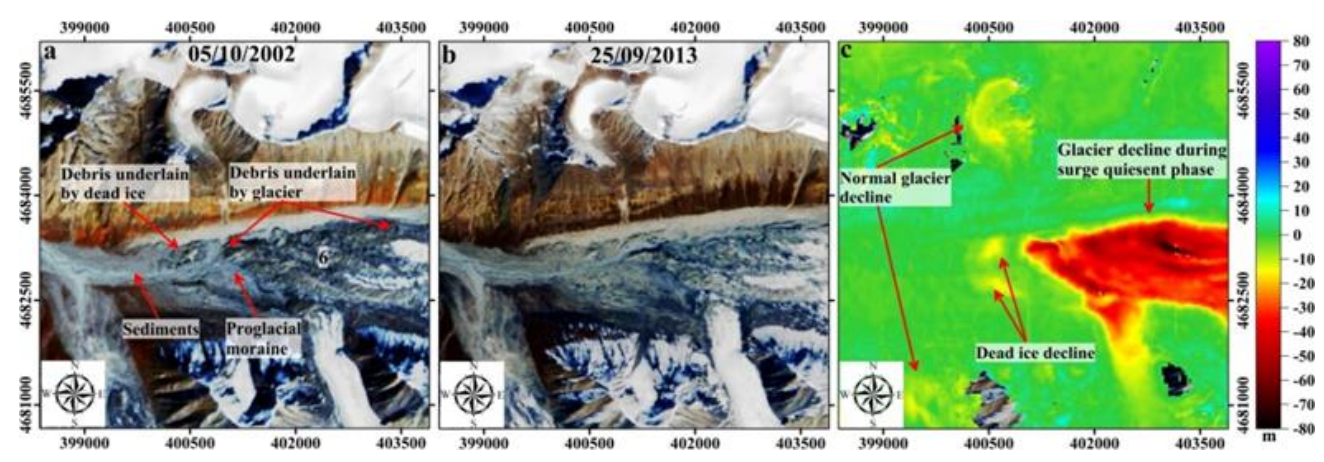

Fig. 9. Landsat images (a)-(b) and surface height changes (c) of the area marked by rectangle B3 in Fig. 5. Images

(a) and (b) were acquired on 5 October 2002 and 25 September 2013, respectively. Number 6 represents the Musktov glacier. In order to give prominence to the targets of interest, the two images are enhanced (band stretched) to the same extent. Projection coordinates (UTM 44N, unit: m) are applied.

\subsection{Mechanism and Features of the Glacier Change in the CTS}

As mentioned in Section 1, due to the variation of altitude, location, orientation, debris cover, surge activity and glacial lakes, even within the same basin, the glacier change patterns can differ sharply. Our measurements are characterized by seasonal and annual synchronization, high 572 observation coverage (78.9\%), fine spatial resolution $(15 \mathrm{~m})$ and acceptable precision. Therefore, a 573 comprehensive picture of the CTS glacier changes was revealed. In this section, we interpret the glacier change mechanisms and features from six aspects. 
Section 4.2 partly illustrated the effect of altitude. The inhomogeneity of the average glacier thickness change of the sub-regions was primarily caused by altitude variation. The lower regions saw a more severe glacier decline. It was shown and is generally accepted that lower altitudes warm up faster than higher ones. Furthermore, the transformation of fresh snow to glacier ice takes several years and requires sub-zero temperatures (Shi et al., 2008). The glaciers which have source area in lower altitudes basically have smaller sizes, and are more susceptible to warming since they hold less area to preserve new precipitation (Ren, 1990; Hambrey and Alean, 2004). Accordingly, the accumulation zones of the glaciers in the lower regions also suffered remarkable mass loss (see Table 3). Likewise, for two adjacent glaciated centres with similar topography and debris coverage, the one with lower accumulation area ratio will see higher glacier thinning rate, e.g., Arshiirak $(-0.23 \pm$ $0.17 \mathrm{~m} / \mathrm{a})$ vs. Koilu $(-0.17 \pm 0.20 \mathrm{~m} / \mathrm{a})$. In fact, the ablation zones of some of the huge glaciers, such as Southern Inylchek, Tuomuer, Tuge Biliqi and Wu Cuer, also suffered drastic decline (see Table 4). However, these huge glaciers whose tributaries form tree-like pattern and contain many high and broad firn basins. The height changes in the firn basins were mostly positive or neutral (see Fig. 5). In terms of the entire glacier body, the severe mass loss in the ablation zones was partly counteracted by the slight mass gain or neutral mass changes in the accumulation zones.

\subsubsection{Location}

Local topography can affect the distribution of moist air brought by atmospheric circulation or monsoon. Therefore, even under the control of the same air current, the glaciers in one centre may have different chances of receiving precipitation. As Fig. 1 and Fig. 5 show, three of the four major mountain ranges composing HHKTXT follow the west-east direction (Tuomuer, Khan Tengri and Haditor-Harajoriha). The other (Meridian) follows the north-south direction (not marked in Fig. 1) and crosses the Tuomuer and Khan Tengri mountain ranges (Su et al., 1985). The average altitudes of the Meridian, Tuomuer, Khan Tengri and Haditor-Harajoriha mountain ranges are approximately $6400 \mathrm{~m}, 6600 \mathrm{~m}, 6000 \mathrm{~m}$ and $5400 \mathrm{~m}$ a.s.1., respectively. The moist air in the CTS is primarily 

brought by the westerlies (Su et al., 1985; Liu et al., 1998; Shi et al., 2008). With an average altitude of about $6400 \mathrm{~m}$ a.s.l., the Meridian mountain range is capable of blocking and lifting part of the current coming from the west. Hence, the precipitation over the central section of the Meridian mountain range, especially in the windward side (the west), is greater than that in other parts of HHKTXT. Over the long term, it is the enhanced precipitation that guarantees the replenishment of the Southern Inylchek glacier, the largest and fastest-flowing glacier in the Tien Shan (Li et al., 2014). During the observation period, the thickening in its accumulation zone was the most significant among the 17 selected glaciers in HHKTXT (see Fig. 5). However, as one of its large tributaries experienced a large-scale surge, its average accumulation zone thickening rate was slightly lower than that of the $\mathrm{Wu}$ Cuer glacier $(0.09 \pm 0.29 \mathrm{~m} / \mathrm{a}$ vs. $0.12 \pm 0.23 \mathrm{~m} / \mathrm{a})$.

\subsubsection{Orientation}

Mountain glaciers lose mass in two major ways: ablation and evaporation (Ren, 1990; Xie and Liu, 2010). It is also well known that evaporation can be intensified by wind. Therefore, the windward glaciers potentially lose more mass, especially for those with little debris cover. Note that, despite facing the prevailing wind, the Seminova, Musktov, Northern Inylchek and Carind glaciers experienced the most significant decline in HHKTXT, because of surge activities. In the Arshiirak, Koilu, Southern Slope, Intermontane Basin, Northern Slope and Halk Tawu sub-regions, where glacier distribution is relatively even in terms of aspect, the most severe decline occurred in the glaciers facing west. As shown in Fig. 5, among the huge glaciers that have not surged in their trunks (e.g. Southern Inylchek, Tuomuer, Koxkar, Keqi Kete Liekesu, Qungku Ziwayi, Tuge Biliqi, Muzart, Kara Cumai and CN5X046G0048), the west-facing Muzart glacier experienced the most significant decline in its upper reaches. The Southern Inylchek glacier also faces west; however, it enjoys extra precipitation, so the decline in its upper reaches was less. The reason why the east-facing Tuge Biliqi and $\mathrm{Wu}$ Cuer glaciers also experienced significant decline in their upper reaches is explained in Section 5.2.2. More clues can be found by comparing the ablation zone thickness changes. It was the ablation zone of the Muzart glacier that experienced the highest thinning rate $(-0.61 \pm 0.24 \mathrm{~m} / \mathrm{a})$. 
627 Note that the high thinning rate observed on the Wu Cuer glacier $(-0.58 \pm 0.24 \mathrm{~m} / \mathrm{a})$ includes the

628 contribution of surge (as described in Section 5.2.5). According to Xie and Liu (2010), the largest

629 northern tributary of the Wu Cuer glacier was found to climb over the trunk and surge $5 \mathrm{~km}$ in 1959.

630 Table 4 Thickness changes of the 23 prominent glaciers (labelled in Figs. 4-6) in the CTS during 2000-2012.

\begin{tabular}{|c|c|c|c|c|c|c|c|c|c|c|}
\hline No. & Location & Name/RGI ID & $\begin{array}{l}\text { Snowline } \\
\text { (m a.s.l.) }\end{array}$ & AAR & $\begin{array}{c}\text { Total area } \\
\left(\mathbf{k m}^{2}\right)\end{array}$ & $\begin{array}{c}\text { Debris } \\
\text { coverage } \\
(\%)\end{array}$ & $\begin{array}{c}\text { Thickness change } \\
\text { measurement } \\
\text { coverage }(\%)\end{array}$ & $\begin{array}{c}\text { Accumu. zone } \\
\text { thickness change } \\
\qquad(\mathbf{m} / \mathbf{a})\end{array}$ & $\begin{array}{c}\text { Ablation zone } \\
\text { thickness change } \\
\qquad(\mathbf{m} / \mathbf{a})\end{array}$ & $\begin{array}{c}\text { Average } \\
\text { Thickness } \\
\text { change( m/a) }\end{array}$ \\
\hline 1 & ETASAKEK & Kopakovsky & 4312 & 0.46 & 25.2 & $4.5 \%$ & $94.3 \%$ & $0.06 \pm 0.16$ & $-0.48 \pm 0.16$ & $-0.23 \pm 0.16$ \\
\hline 2 & ETASAKEK & Petrova & 4387 & 0.42 & 62.3 & $4.6 \%$ & $94.1 \%$ & $0.07 \pm 0.18$ & $-0.64 \pm 0.16$ & $-0.34 \pm 0.17$ \\
\hline 3 & ETASAKEK & Dschamansu & 4378 & 0.44 & 25.0 & $6.4 \%$ & $95.2 \%$ & $0.11 \pm 0.18$ & $-0.62 \pm 0.16$ & $-0.30 \pm 0.16$ \\
\hline 4 & ETASAKEK & Kaindy & 4313 & 0.61 & 19.2 & $5.6 \%$ & $95.3 \%$ & $0.04 \pm 0.17$ & $-0.71 \pm 0.16$ & $-0.25 \pm 0.16$ \\
\hline 5 & HHKTXT & Seminova & 4103 & 0.65 & 63.2 & $7.8 \%$ & $99.1 \%$ & $0.06 \pm 0.23$ & $-0.73 \pm 0.23$ & $-0.22 \pm 0.23$ \\
\hline 6 & HHKTXT & Musktov & 4124 & 0.53 & 74.0 & $9.0 \%$ & $94.7 \%$ & $0.02 \pm 0.25$ & $-0.73 \pm 0.25$ & $-0.33 \pm 0.25$ \\
\hline 7 & HHKTXT & Northern Inylchek & 4359 & 0.58 & 175.0 & $15.1 \%$ & $74.0 \%$ & $-0.14 \pm 0.23$ & $-0.51 \pm 0.25$ & $-0.30 \pm 0.24$ \\
\hline 8 & HHKTXT & Southern Inylchek & 4427 & 0.63 & 565.9 & $16.7 \%$ & $80.6 \%$ & $0.09 \pm 0.29$ & $-0.50 \pm 0.23$ & $-0.13 \pm 0.27$ \\
\hline 9 & HHKTXT & Carind & 4304 & 0.60 & 116.1 & $19.2 \%$ & $78.4 \%$ & $-0.14 \pm 0.23$ & $-0.53 \pm 0.23$ & $-0.29 \pm 0.23$ \\
\hline 10 & HНKTXT & Tuomuer & 4345 & 0.66 & 324.4 & $20.2 \%$ & $77.9 \%$ & $-0.03 \pm 0.24$ & $-0.38 \pm 0.23$ & $-0.15 \pm 0.24$ \\
\hline 11 & HHKTXT & Koxkar & 4423 & 0.49 & 77.3 & $29.8 \%$ & $76.2 \%$ & $-0.06 \pm 0.24$ & $-0.25 \pm 0.24$ & $-0.16 \pm 0.24$ \\
\hline 12 & HHKTXT & Western Qung Telian & 4371 & 0.66 & 133.2 & $16.4 \%$ & $59.3 \%$ & $-0.17 \pm 0.32$ & $-0.29 \pm 0.23$ & $-0.22 \pm 0.29$ \\
\hline 13 & HHKTXT & Eastern Qung Telian & 4255 & 0.63 & 72.2 & $24.6 \%$ & $58.9 \%$ & $-0.04 \pm 0.27$ & $-0.19 \pm 0.23$ & $-0.10 \pm 0.25$ \\
\hline 14 & HНKTXT & Keqi Kete Liekesu & 4247 & 0.59 & 81.0 & $21.4 \%$ & $56.8 \%$ & $-0.08 \pm 0.25$ & $-0.17 \pm 0.23$ & $-0.11 \pm 0.24$ \\
\hline 15 & НHКТХТ & Qungku Ziwayi & 4194 & 0.57 & 56.0 & $21.6 \%$ & $80.7 \%$ & $-0.07 \pm 0.25$ & $-0.27 \pm 0.23$ & $-0.16 \pm 0.24$ \\
\hline 16 & HHKTXT & Tuge Biliqi & 4264 & 0.68 & 264.2 & $17.0 \%$ & $49.4 \%$ & $0.05 \pm 0.28$ & $-0.47 \pm 0.23$ & $-0.12 \pm 0.27$ \\
\hline 17 & HHKTXT & Wu Cuer & 4242 & 0.59 & 185.6 & $15.2 \%$ & $80.5 \%$ & $0.12 \pm 0.23$ & $-0.58 \pm 0.24$ & $-0.16 \pm 0.24$ \\
\hline 18 & HНKTXT & Muzart & 4262 & 0.56 & 165.4 & $16.9 \%$ & $74.2 \%$ & $0.07 \pm 0.23$ & $-0.61 \pm 0.24$ & $-0.23 \pm 0.24$ \\
\hline 19 & HНKTXT & Kara Cumai & 4217 & 0.60 & 54.8 & $24.0 \%$ & $67.3 \%$ & $-0.11 \pm 0.24$ & $-0.42 \pm 0.24$ & $-0.24 \pm 0.24$ \\
\hline 20 & HНKTXT & Archur Leter & 4199 & 0.46 & 43.8 & $14.76 \%$ & $89.1 \%$ & $0.03 \pm 0.23$ & $-0.28 \pm 0.25$ & $-0.14 \pm 0.24$ \\
\hline 21 & HHKTXT & CN5X046G0048 & 4072 & 0.53 & 71.0 & $20.7 \%$ & $75.0 \%$ & $-0.02 \pm 0.24$ & $-0.39 \pm 0.24$ & $-0.19 \pm 0.24$ \\
\hline 22 & BHT & CN5X046E0089 & 3946 & 0.69 & 40.1 & $9.2 \%$ & $90.9 \%$ & $0.01 \pm 0.28$ & $-0.65 \pm 0.26$ & $-0.19 \pm 0.27$ \\
\hline 23 & BHT & CN5X045D0025 & 3835 & 0.64 & 16.0 & $1.7 \%$ & $99.6 \%$ & $0.24 \pm 0.26$ & $-0.90 \pm 0.25$ & $-0.16 \pm 0.26$ \\
\hline
\end{tabular}

\subsubsection{Debris Cover}

In theory, due to the albedo reduction or heat insulation effects, a thin or thick debris cover can

633 aggravate or attenuate the ice ablation, respectively (the critical thickness ranges from 2 to $8 \mathrm{~cm}$ )

634 (Hagg et al., 2008, Xie et al., 2007). Without other impacts, a hyperbolic dependence can be 635 determined between debris thickness and ablation rate (Khodakov, 1972). The glacier debris is 
mainly produced by the scraping during avalanches and glacier motion (Xie and Liu, 2010).

637 Basically, a regular-shaped glacier bed and a small altitude drop mean less frequent avalanches and 638 slower glacier motion, and therefore thinner debris. For glaciers with little debris cover, the decline 639 on trunks is increasingly strong towards the terminus. Receding is the major form of mass loss. 640 Among this kind of glacier, the Archur Leter, Dschamansu and Kaindy glaciers declined at rates comparable to the large surge glaciers. Glacier surfaces in ETASAKEK and BHT are basically exposed to air, and the strongest decline is supposed to occur at the glacier terminuses. However, since the glaciers have been receding since before 2000, the maximum thinning was found in a slightly higher part (see the inset panels in Figs. 3 and 5). The Archur Leter glacier is a special case. Its southern tributary has a thick debris cover, while the much larger northern tributary has little debris. When the two tributaries meet, the southern one bypasses the northern one rather than integrating with it, i.e., the two tributaries are independent and the debris-covered snout belongs to the southern tributary. For the northern tributary, it was the terminus that saw the greatest decline 649 (see the inset panel in Fig. 5).

In contrast, debris cover is fairly common for the tree-like glaciers flowing down from mountains with lofty horns/arêtes. Apart from the large altitude drop, the motion of large glaciers is towards the terminus. Although thin debris cover can reduce albedo and aggravate the ice ablation, the decline was slight in the upper reaches of most of the huge glaciers (e.g. Southern Inylchek, Eastern Qung Telian, Keqi Kete Liekesu, Qungku Ziwayi and Kara Cumai), because of the temperature drop with increasing altitude. Only in a few glaciers could the aggravating effect of thin debris be observed. The trunks of the Tuomuer, Tuge Biliqi, Wu Cuer and Muzart glaciers are fairly long and have a relatively low altitude. Hence, the aggravating effect of thin debris applied. Fig. 10 shows that, in the tongue of the Tuomuer $(8.5 \sim 18 \mathrm{~km})$, Tuge Biliqi $(10 \sim 27.5 \mathrm{~km})$, Wu Cuer 


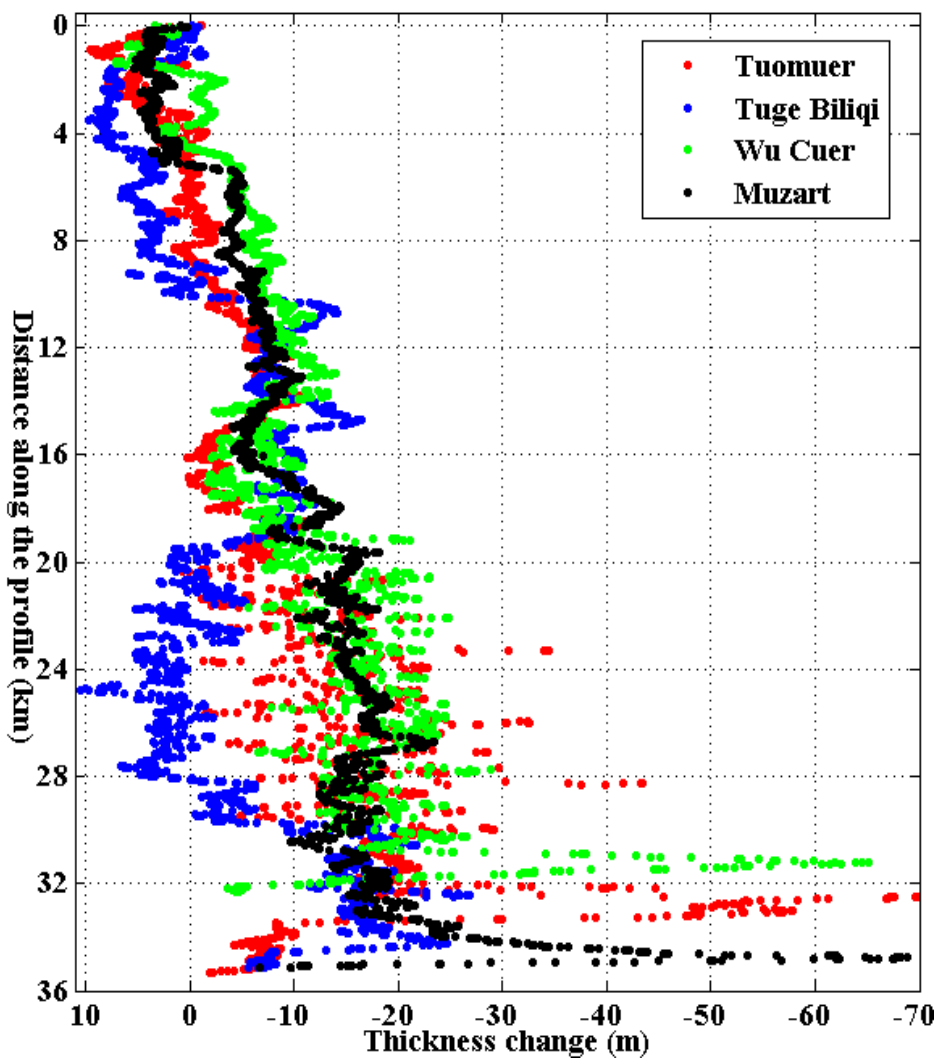

Fig. 10. Longitudinal thickness change profiles of the Tuomuer (glacier No. 10), Tuge Biliqi (glacier No. 16), Wu

Cuer (glacier No. 17) and Muzart (glacier No. 18) glaciers. Profile locations are denoted by the dashed black lines in Fig. 5.

In theory, the ablation will cease when the debris thickness reaches 1-2 m (Hagg et al., 2008, Xie et al., 2007). Hence, the intensity decline should reach the peak in a higher section and then become increasingly weak towards the terminus. However, in HHKTXT, only the Koxkar glacier was found to decline in such a way (see Fig. 5). Glaciers in HHKTXT belong to the poly-thermal type (Shi et al., 2008), i.e., at the base of the ablation zone, the temperature is close to the ice melting point. The surface meltwater can flow down into the glacier body via crevasses or moulins and survive in or beneath the ice. A field investigation on the Koxkar glacier found that during the ablation period, the surface meltwater has a positive temperature, varying between 0.1 and $4^{\circ} \mathrm{C}$ (Xie et al., 2007). As a result of heat conduction, the inner ablation can be significantly promoted by the englacial or subglacial drainage, especially near the main outlet. Furthermore, the coexistence of 
very thick debris and severe inner ablation prompted the collapse of the englacial melt

678 holes/funnels/ditches, and therefore supraglacial lakes and ice cliffs formed easily (Xie et al., 2007).

679 In turn, the supraglacial lakes and ice cliffs aggravated the glacier decline (see Fig. 11). 680 Consequently, the glaciers covered by thick debris (1 5 m) (Xie and Liu, 2010) still suffered a 681 severe decline, and even saw the greatest decline near their terminuses. Meanwhile, the surface of 682 ablation zones appears densely pitted, which becomes a unique feature of gigantic glaciers (see the thickness changes of the Southern Inylchek, Tuomuer, Tuge Biliqi, Wu Cuer and Muzart glaciers in

Fig. 5 and Table 4). In general, the effects of meteorological and englacial thermal conditions can counteract much of the effect of debris. For the entire glacier body, the hyperbolic dependence is very difficult to establish.
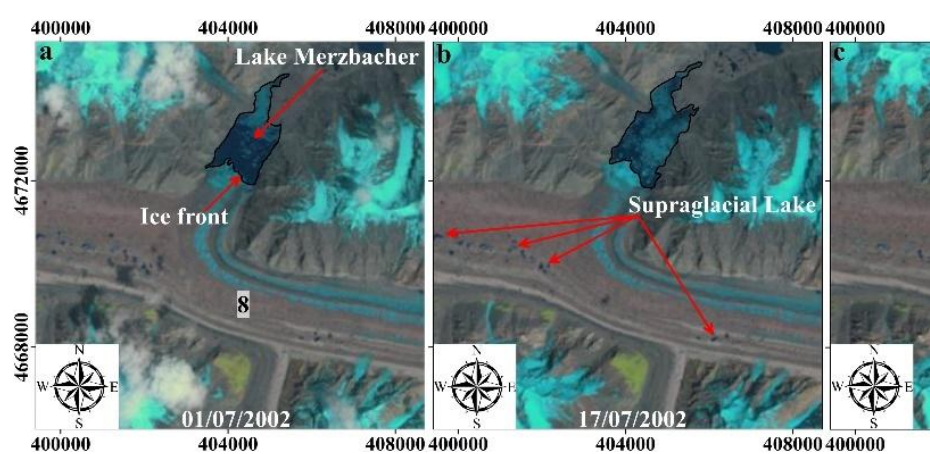

404000

$408000400000 \quad 404000$

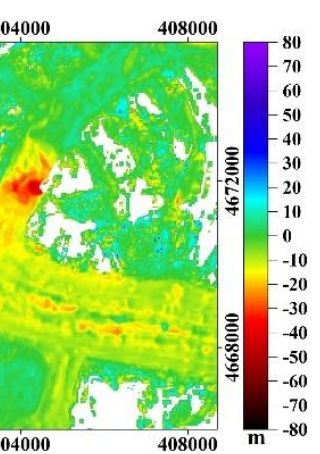

Fig. 11. Landsat images (a)-(c) and surface height changes (d) of the area marked by rectangle B4 in Fig. 5.

Images (a)-(c) were acquired on 1 July 2002, 17 July 2002 and 18 August 2002, respectively. Number 8 represents the Southern Inylchek glacier. Projection coordinates (UTM 44N, unit: m) are applied.

However, although the heavy debris could not prevent the ablation, its attenuating effects were

considerable. We can corroborate this conclusion from three aspects. Firstly, it is the heavy debris that enables the glaciers in HHKTXT to extend to a lower altitude ( $2675 \mathrm{~m}$ a.s.l) relative to those in ETASAKEK ( 3200 m a.s.l) and BHT ( 3050 m a.s.l). The largest glacier, the Southern Inylchek glacier, has barely receded since the 1850s because of its thick debris cover (Xie and Liu, 2010).

Secondly, in addition to the contrasting effects of thin and thick debris, Fig. 10 also shows that, for the Tuomuer (21 30 km), Tuge Biliqi (30 33.5 km), Wu Cuer (20 30.5 km) and Muzart (27 33 km) glaciers, the decline was relatively regular within a long section of their lower reaches (the same 
applies for the Southern Inylchek glacier, see Fig. 5). This phenomenon indicates that the effects of meteorological condition variations were isolated. Thirdly, in terms of the non-surge glaciers, within the same altitude interval (3200 3700 m a.s.1), the regional thinning rate in HHKTXT (excluding the Northern Slope) $(-0.73 \pm 0.24 \mathrm{~m} / \mathrm{a})$ was less than that in ETASAKEK $(-0.93 \pm 0.17 \mathrm{~m} / \mathrm{a})$ and BHT $(-0.75 \pm 0.26 \mathrm{~m} / \mathrm{a})$. Note that this pattern is distinct from that in the Pamir, Spiti Lahaul, Karakoram and Everst areas reported earlier (Kääb et al., 2012; Gardelle et al., 2013).

\subsubsection{Glacier Surge}

Surge is a periodic glacier activity. Each period includes an active phase and a quiescent phase. During the active phase, a huge volume of ice moves rapidly from the reservoir zone to the receiving zone, causing remarkable heightening and lowering in the lower and upper reaches, respectively. During the quiescent phase, the receiving zone was lowered with a high and even intensity, because the entire bulk of ice/firn transferred to the lower reaches is prone to melting, while the reservoir zone was heightened again. In the late quiescent phase, the heightened ice front begins to advance slowly; however, with a speed much lower than after the start of the surge. The active phase usually lasts several days to several years, and is much shorter than the quiescent phase, which can last for tens of years (Xie and Liu, 2010). An assemblage of surge activities can be clearly observed in the region shown in Fig. 12. Within this region, six glaciers showed remarkable height changes (glaciers 25-30, see Fig. 12a). The upstream and downstream parts of glaciers 27 and 28 experienced dramatic lowering and heightening, respectively. The sharp contrast indicates that these two glaciers surged between 2000 and 2012. A severely lowered region was observed in front of the receiving zone of glacier 28. Such lowering can be ascribed to the intensive decline during the last quiescent phase. It also indicates that during the recent surge, glacier 28 did not advance as far as the last time. For glacier 25, the heightening was dramatic and dominant, and yet a small area of significant lowering occurred in its distal area, indicating that glacier 25 had been in the late quiescent or early active phase by 30 January 2012. Glacier 26 also surged during the observation period (see Fig. 5). The heightening in its upstream part can be seen as a sign of the quiescent phase. Glacier 29 had the least 
surface lowering among the six glaciers. In addition, the lowering was confined to the downstream part, and no heightening occurred in the other parts, suggesting that it was caused by normal glacier decline. As for glacier 30, its downstream part lowered significantly while the upstream part heightened only slightly. The uneven lowering and slight contrast are not convincing evidence of the quiescent phase.

In the optical image acquired on 5 October 2002 (Fig. 12a), glacier 27 had a steep and regular ice front, while glaciers 25, 28 and 29 had gentle and irregular ice fronts, suggesting that glacier 27 was advancing and the other three were receding (Hambrey and Alean, 2004). Meanwhile, dense and regular crevasses could be discerned in the midstream of glacier 27 (corresponding to the location of the outflow zone (see Fig. 12d)), suggesting that the ice was flowing rapidly. Comparing the optical view on 5 October 2002 (Fig. 12a) with that on 25 September 2013 (Fig. 12b), we found that glacier 27 advanced while glaciers 25, 28 and 29 receded from 2002 to 2013, and during the following year, glacier 27 clearly shrunk (see Fig. 12b and c). Unlike glacier 27, glacier 28 saw its snout broaden rather than advance during the recent surge (We delineated the tongues of glacier 28 in the two periods since they appeared blurry). This tallies with the earlier speculation that glacier 28 did not advance as much as last time. Furthermore, the front of glacier 25 had become steep and regular by shifted to advancing. However, it had not reached the terminus position by 5 October 2002, i.e., it was in the late quiescent phase. In fact, during the following year, glacier 25 advanced only $\sim 60 \mathrm{~m}$ (by comparing the optical view on 25 September 2013 with that on 12 September 2014). Therefore, the deduction that glacier 25 had been in the late quiescent or early active phase by 30 January 2012 was true. For glacier 30, none of the ice exposed in the downstream and the views on the three days show little changes, indicating that the downstream part was almost stagnant. Basically, the snout stagnancy is accompanied by strong down-wasting (Quincey et al., 2009), which can result in intensive but uneven lowering. A new ice layer was added to the upstream, which should be the 

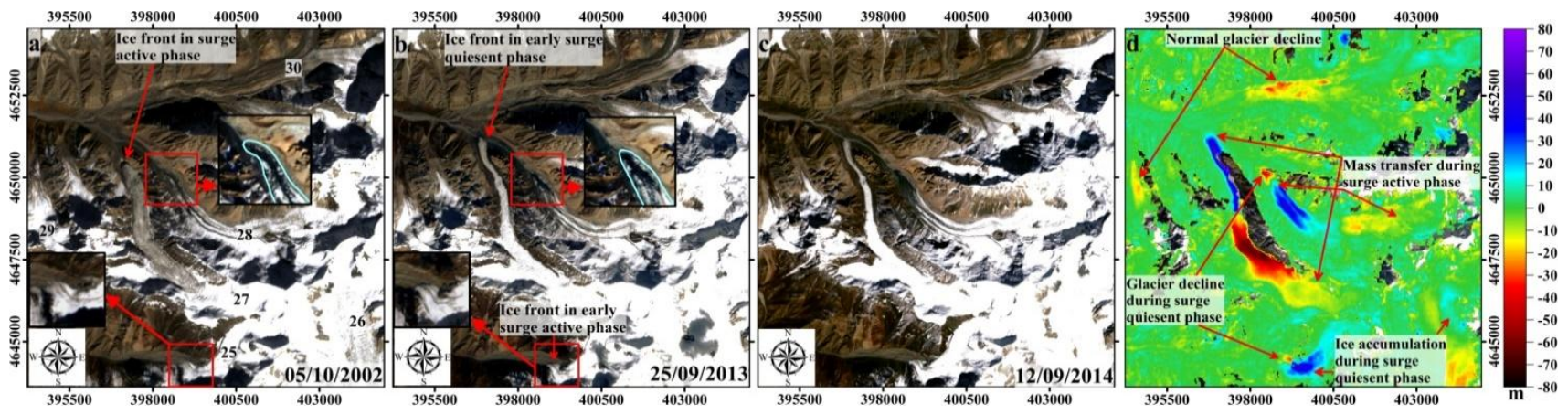

Fig. 12. Landsat images (a)-(c) and surface height changes (d) of the area marked by rectangle B4 in Fig. 5.

Images (a)-(c) were acquired on 5 October 2002, 25 September 2013 and 12 September 2014, respectively.

Numbers 25-30 represent the different glaciers. The light blue lines in (a) and (b) denote the glacier tongue

outlines. Projection coordinates (UTM 44N, unit: m) are applied.

Besides, we found the largest glacier of the Biyeek mountain range, CN5X045D0025 (see Fig.

6), may belong to surge type. The CN5X045D0025 and CN5X046E0089 (see Fig. 6) glaciers in

BHT were selected for specific measurements. As expected, the average thinning rates observed in

the ablation zones of the two glaciers were both very high $(-0.65 \pm 0.26 \mathrm{~m} / \mathrm{a}$ and $-0.90 \pm 0.25 \mathrm{~m} / \mathrm{a})$.

However, in terms of the accumulation zones, the CN5X046E0089 glacier remained almost the same

$(0.01 \pm 0.28 \mathrm{~m} / \mathrm{a})$ while the lower and smaller CN5X045D0025 glacier gained mass at a remarkable

rate $(0.24 \pm 0.26 \mathrm{~m} / \mathrm{a})$. In front of the terminus of the CN5X045D0025 glacier, we found no obvious

historic moraines, which was anomalous relative to the surrounding cases. Hence, it is likely that the

CN5X045D0025 glacier had surged before 2000.

In general, surge glaciers are common in the west slope of the Meridian mountain range and the

south slope of the Tuomuer mountain range, but are scarce in the north slope of the Haditor-

Harajoriha mountain range and the entire region of BHT. The largest surge occurred in the trunk of

the Northern Inylchek glacier, which can be judged from the size of receiving zone and the intensity of decline. These two points manifest the large altitude drop and abundant precipitation can 
771 significantly promote the glacier surge. Due to the surge activity, the Northern Inylchek glacier 772 shares similar precipitation condition and orientation with the Southern Inylchek glacier but 773 experiences quite different thickness changes. The reason why surge did not occur in the trunk of the 774 Southern Inylchek glacier may be ascribed to glacier shapes. As shown in Fig. 5, the tributaries of the Northern Inylchek glacier are short and densely aligned along the trunks, while the tributaries of the Southern Inylchek glacier are much fewer and longer. For the Northern Inylchek glacier, the influx of mass collected on the mountain ridges into the trunk costs much shorter time, which 778 increases the possibility of surge. m/a, see Fig. 5), while the mass gain in the accumulation zones was far from being enough to cover

The ablation zones of glaciers which had surged in their trunks before 2000, e.g., Seminova, Musktov, Northern Inylchek, Carind and the largest northern tributary of the Wu Cuer glacier, experienced remarkable thinning during 2000-2012 (mostly 30 40 m/a, but the highest was over 78 the mass loss (see Fig. 5). Furthermore, the Musktov, Northern Inylchek and Carind glaciers surged again; however, with much lower magnitudes than the former surges. Note that for the Musktov glacier, there was no transition area between the lowered downstream and heightened upstream, and more importantly, the heightened zone had a regular and forward-inclining front, indicating that it was in a surge active phase in 2012. In general, the surge glaciers in HHKTXT experienced a greater decline than the non-surge ones $(-0.27 \pm 0.25 \mathrm{~m} / \mathrm{a}$ vs $-0.19 \pm 0.25 \mathrm{~m} / \mathrm{a})$, which was distinct from the pattern in the Karakoram reported earlier (Gardelle et al., 2012). The cycle and magnitude of glacier surge can be influenced by climate change. Adequate flow resistance to allow sufficient accumulation in the restoring zone is the basis of another surge (Lingle and Fatland, 2003; Flowers et al., 2011). Smaller surge amplitudes indicate earlier arrival. We believe that such a phenomenon should be ascribed to the acceleration of englacial stress change and the enhancement of subglacial lubrication. Both factors reduce the flow resistance. More precisely, the former is caused by the unusual thinning in the lower reaches rather than the increase in the firn basin load in the upper reaches. A precipitation increase did accompany the temperature rise in HHKTXT (Sheng et al., 
2009a). However, even for the Southern Inylchek glacier, which possesses the strongest advantage to

798

799 preserve precipitation, the accumulation in its firn bases increased only slightly ( 10 m, see Fig. 5). In contrast, rapid thinning in the lower reaches can facilitate the transformation from compressional flow to extensional flow, and therefore reduce the critical load for surge outburst. As mentioned above, surface meltwater can flow down into the glacier body and survive in or beneath the ice. The intensified ablation contributes more meltwater to the glacier base, and therefore strengthens the lubrication. From the above two aspects, external climate changes can significantly influence glacier surges. The surge itself does not deplete the mass; however, it puts extra mass in 'dangerous' places relative to the normal glacier flow. A temperature rise can stimulate a glacier to surge and lose more of the mass preserved in the upper reaches.

\subsubsection{Glacial Lakes}

In Section 5.2.4, we have mentioned that supraglacial lakes can promoted the glacier surface decline. Here, we examine two prominent proglacial lakes in the CTS. Lake Petrova, the largest glacial lake in ETASAKEK (see Figs. 1 and 7), expanded remarkably during the observation period. This lake emerged because of the Petrova glacier receding. As the ice front was calved into Lake Petrova, the Petrova glacier receded at a speed higher than that of the surrounding land-terminated glaciers. Taking the Sary-Tor glacier (glacier 24 in Fig. 8) as an example, from 17 August 1999 to 31 August 2013, it receded $393 \pm 15 \mathrm{~m}$. If the Petrova glacier were also land-terminated, it should recede slower than the Sary-Tor glacier, because of its thicker tongue and faster flow (meaning more rapid mass replenishment). In fact, the Petrova glacier receded $805 \pm 15 \mathrm{~m}$ during the observation time. Meanwhile, due to the thermal erosion of the lake water that was squeezed into the tongue bottom, the Petrova glacier's ablation zone thinned more intensively than those of the Kaindy and Dschamansu glaciers, two big land-terminated glaciers in the Arshiirak mountain range. Within the same altitude range (3820 3920 $\mathrm{m}$ a.s.1.), the thinning rates of these three glaciers were $-2.79 \pm 0.16$ $\mathrm{m} / \mathrm{a},-2.39 \pm 0.16 \mathrm{~m} / \mathrm{a}$ and $-2.01 \pm 0.20 \mathrm{~m} / \mathrm{a}$, respectively. If the comparison was conducted among the thickness changes within the $100 \mathrm{~m}$ altitude range from the terminus, the discrepancy would be 
more obvious $(-3.03 \pm 0.16 \mathrm{~m} / \mathrm{a},-2.39 \pm 0.16 \mathrm{~m} / \mathrm{a}$ and $-2.21 \pm 0.20 \mathrm{~m} / \mathrm{a}$, respectively). Due to the

824 dramatic thinning and rapid receding of the Petrova glacier, Lake Petrova's water capacity is likely 825 to further increase in the future. Steps should be taken to avoid lake outburst, which could cause 826 flooding in the downstream valley.

The other example is Lake Merzbacher, a big proglacial lake dammed by the Southern Inylchek glacier's tributary. In the past, this lake has caused severe flooding almost every year

(Sheng et al., 2009b).Mayer et al. (2008) reported that, during the ablation period, from the ice dam to the junction of the tributary and trunk, the glacier flow velocity increases dramatically to replenish the mass loss caused by calving, and the ice dam subsides after lake outburst. As shown in Fig. 11a, by 1 July 2002, the Merzbacher Lake had been filled with meltwater. Over the following 17 days, the lake area expanded by $25 \%$ (see Fig. 11b), and a greater proportion of its surface was filled with

In June 1981 and July 2004, the Institute of Glaciology and Geocryology belonging to the Chinese Academy of Sciences used ground radio echo sounding to measure the Koxkar glacier's thickness. The results indicated that the average ice thinning rates were $-0.48 \mathrm{~m} / \mathrm{a}$ and $-0.75 \mathrm{~m} / \mathrm{a}$ along the two cross profiles in the glacier tongue, with altitudes of $3170 \mathrm{~m}$ and $3300 \mathrm{~m}$ a.s.1., respectively (Xie et al., 2007). Regarding the DEM errors, we extracted the average thickness changes from the buffer zones along the cross profiles $( \pm 15 \mathrm{~m})$. Even though the monitoring time period did not fully overlap with ours, the results of the two measurements are close $(-0.41 \mathrm{~m} / \mathrm{a}$ and 
southern slopes of the Tuomuer mountain range between 1999 and 2009, based on the difference

850

between the SRTM DEM and the SPOT5/HRG DEM. In this similar region, the glacier thinning rate they derived $(-0.26 \pm 0.21 \mathrm{~m} / \mathrm{a})$ was slightly higher than ours $(-0.19 \pm 0.23 \mathrm{~m} / \mathrm{a})$. Furthermore, the captured surges were consistent with ours (e.g. Western Qung Telian glacier). More recently, Shangguan et al. (2015) utilized the SRTM, ALOS-PRISM (2006) and SPOT5-HRG (2007) DEMs to study the mass changes of the Inylchek glacier. They reported that between 1999 and 2007, the Northern and Southern Inylchek glaciers thinned at rates of $-0.67 \pm 0.54 \mathrm{~m} / \mathrm{a}$ and $-0.33 \pm 0.54 \mathrm{~m} / \mathrm{a}$, respectively. Accordingly, our results were $-0.30 \pm 0.24 \mathrm{~m} / \mathrm{a}$ and $-0.13 \pm 0.27 \mathrm{~m} / \mathrm{a}$, respectively. The discrepancy is dramatic for the Northern Inylchek glacier, and may have been caused by the difference between the rates of missing observations in upper reaches and the difference between the calculations of $\mathrm{C}$-band penetration depth. We note that in the thickness change map presented by Shangguan et al. (2015), the signal patterns over glacier tongues (lower regions) looked quite similar to ours. Additionally, they detected an obvious heightening of more than $100 \mathrm{~m}$ between 1974 and 1999 in the tongue of the Northern Inylchek glacier. The area change measurements indicated that a surge between 1990 and 1999 could account for the heightening. This finding is consistent with the drastic decline (up to $-70 \mathrm{~m}$ ) in the Northern Inylchek glacier's tongue observed in our study.

\subsubsection{Regional Scale}

To date, a number of early 21 st Century region-wide glacier mass change measurements have been obtained in the Tien Shan (Jacob et al, 2012; Gardner et al., 2013; Farinotti et al., 2015). Gardner et al. (2013) estimated the High Mountain Asia glacier mass budget for 2003-2009 based on ICE/Sat GLAS measurements, and in the Tien Shan, they obtained an regional glacier thinning rate of $-0.58 \pm 0.21 \mathrm{~m} / \mathrm{a}$. Further extending the ICE/Sat GLAS data processing options of Gardner et al. (2013) in 15 different ways, Farinotti et al. (2015) derived a regional thinning rate of $-0.46 \pm$ $0.25 \mathrm{~m} / \mathrm{a}$ for the Tien Shan glaciers for 2003-2009 (a density of $900 \mathrm{~kg} / \mathrm{m}^{3}$ was adopted). The GRACE measurements of Jacob et al. (2012) also covered the Tien Shan, and the 2003-2010 glacier mass budget was found to be $-5 \pm 3 \mathrm{Gt} / \mathrm{a}$ (one sigma level). If the Tien Shan glacier area in Gardner 
et al. (2013) was adopted for conversion, the regional thickness change in Jacob et al. (2012) would be $-0.38 \pm 0.23 \mathrm{~m} / \mathrm{a}$. Among the three studies, only Farinotti et al. (2015) further divided the Tien Shan into sub-regions. For similar regions to ours (including the defined CTS, Halik Shan and Inner Ranges in Farinotti et al. (2015)), the regional glacier thinning rate was $-0.31 \pm 0.41 \mathrm{~m} / \mathrm{a}$ (areaweighted average). Our result $(-0.24 \pm 0.22 \mathrm{~m} / \mathrm{a})$ agrees well with that of Farinotti et al. (2015).

It should be noted that our CTS glacier thickness change rate is different from Jacob et al.'s (2012) Tien Shan glacier thickness change rate. This difference $(-0.24 \pm 0.22 \mathrm{~m} / \mathrm{a}$ vs. $-0.38 \pm$ $0.23 \mathrm{~m} / \mathrm{a}$ ) is consistent with the difference between Farinotti et al.'s (2015) CTS (including the defined CTS, Halik Shan and Inner Ranges in Farinotti et al. (2015)) and Tien Shan glacier thickness change rates based on ICESat/GLAS measurements $(-0.31 \pm 0.41 \mathrm{~m} / \mathrm{a}$ vs. $-0.46 \pm 0.25 \mathrm{~m} / \mathrm{a})$. Glaciers in the CTS seem more stable than those in other Tien Shan sub-regions. In Farinotti et al. (2015), the glacier thinning rates based on ICESat/GLAS measurements were $-0.74 \pm 0.59 \mathrm{~m} / \mathrm{a}$ and $-0.80 \pm 0.52 \mathrm{~m} / \mathrm{a}$ for Borohoro (Eastern Tien Shan) and Ile-Kungoy Alatau (Northern Tien Shan), respectively, which are dramatically higher than the rate for the CTS. The inter-region variability of glacier thickness change can be partly corroborated by the glacier area change measurements. Osmonov et al. (2013) reported that the glacier area in the Sary-Jaz river basin (i.e. the part of the Kumalik river basin within Kyrgyzstan, CTS) shrank by $\sim 0.19 \%$ per year between 1990 and 2010. This rate is very much lower than those of other Tien Shan regions between 2000 and 2007 reported by Narama et al. (2010), e.g., $~ 0.71 \%$ per year for Pskem (Western Tien Shan), $\sim 0.57 \%$ per year for lli-kungöy (Northern Tien Shan) and $\sim 0.57 \%$ per year for At-Bashy (Inner Tien Shan). The situations in the last decades of the 20th century were similar, e.g., $\sim 0.09 \%$ per year for the Aksu Basin (CTS, the major part of our study area) between 1963 and 1999 (Liu et al., 2006); 0.09\% per year for the Inylchek region (CTS) and $\sim 0.08 \%$ per year for the Tuomuer region (CTS) between 1975 and 2008 (Pieczonka and Bolch, 2015); 0.48\% per year for Ala Archa (Northern Tien Shan) between 1981 and 2003 (Aizen et al., 2006); 0.63\% per year for Pskem (Western Tien Shan), $\sim 0.40 \%$ per year for 1li-kungöy (Northern Tien Shan), $\sim 0.40 \%$ per year for At-Bashy (Inner Tien Shan), and $\sim 0.30 \%$ per 
year for SE-Fergana (Inner Tien Shan) between 1970 and 2000 (Narama et al., 2010); and 0.35\%

902 903 per year for the Middle Chinese Tien Shan (Eastern Tien Shan) between 1963 and 2000 (Li et al., 2006).

Among the nine studied sub-regions in Gardelle et al. (2013), the east four under the control of the westerlies, i.e. Pamir, Western Karakoram, Eastern Karakoram and Hindu Kush, have seen positive or slight negative glacier thickness change rates $(0.16 \pm 0.15 \mathrm{~m} / \mathrm{a}, 0.11 \pm 0.21 \mathrm{~m} / \mathrm{a}, 0.13 \pm$ $0.16 \mathrm{~m} / \mathrm{a}$ and $-0.14 \pm 0.19 \mathrm{~m} / \mathrm{a}$ ), while the west four under the control of the Indian and Southeast Asian summer monsoons, i.e. Hengduan Shan, Bhutan, Everest and West Nepal, have seen considerable negative glacier thickness change rates $(-0.39 \pm 0.16 \mathrm{~m} / \mathrm{a},-0.26 \pm 0.15 \mathrm{~m} / \mathrm{a},-0.31 \pm$ $0.16 \mathrm{~m} / \mathrm{a}$ and $-0.38 \pm 0.15 \mathrm{~m} / \mathrm{a})$. The other sub-region located in the transition zone, i.e., Spiti Lahaul, has seen the most negative glacier thickness change rate $(-0.53 \pm 0.15 \mathrm{~m} / \mathrm{a})$. In addition, Gardner et al. (2013) reported that the West Kunlun region under the control of the westerlies has seen a glacier thickness change rate of $0.17 \pm 0.15 \mathrm{~m} / \mathrm{a}$. Hence, compared to the other westerly-controlled regions, the CTS $(-0.24 \pm 0.22 \mathrm{~m} / \mathrm{a})$ has the worst glacier state, but compared to the monsoon-controlled regions, it has a better glacier state.

\section{Conclusions}

In this paper, a geodetic method was adopted to measure the region-wide glacier thickness changes in the CTS during 2000-2012. A new DEM extracted from TanDEM-X CoSSC images was subtracted from the SRTM DEM. Based on the glacial mask delineated from Landsat L1T images, we removed the systematic height difference bias related to the horizontal shift, baseline estimation residue and terrain aspect/slope/curvature. The glacier snowline was also delineated to differentiate the thickness change in the accumulation and ablation zones. Glaciers covering $7239.8 \pm 527.2 \mathrm{~km}^{2}$ in the CTS were studied. The overall glacier thinning rate was $-0.24 \pm 0.22 \mathrm{~m} / \mathrm{a}$, which differs slightly from the result based on ICESat/GLAS measurement reported earlier. Moderate thinning $(-1.56 \pm 2.64 \mathrm{~m})$ and strong thinning $(-4.80 \pm 2.64 \mathrm{~m})$ were observed above and below the average 
snowline (4178 $\mathrm{m}$ a.s.l.) respectively. The average thickness change rates of the 10 second-level subregions ranged from $-0.17 \pm 0.20 \mathrm{~m} / \mathrm{a}$ to $-0.37 \pm 0.16 \mathrm{~m} / \mathrm{a}$. And the 23 selected individual glaciers are with an average rate ranging from $-0.10 \pm 0.25 \mathrm{~m} / \mathrm{a}$ to $-0.34 \pm 0.17 \mathrm{~m} / \mathrm{a}$. In general, the rate of glacier decline in the CTS appears to be behind that of other parts of the Tien Shan (Northern, Western, Eastern and Inner Tien Shan) as reported from previous studies. However, the situation in the CTS is alarming since decline is prevailing among a huge number of glaciers. We derived a moderate average thinning rate since the drastic thinning in the ablation zones has been balanced by the slight thinning in the broad accumulation zones. In fact, the aggregate glacier mass loss across the region is considerable. Owing to the huge volume of ice storage in the CTS, the impact of glacier decline will maintain on increasing the downstream runoff in recent decades.

The glacier thickness change results were analysed and interpreted from multiple aspects. We 937 first illustrated the typical height change patterns based on visual interpretation, e.g., normal glacier mass loss/gain, landslides, mining, reclamation, and dead ice decline. This illustration indicated that our method could achieve reasonable surface height changes. We then highlighted the glacier change 940 features and behaving rules in the CTS. The factors causing the inhomogeneity of the glacier thickness changes, such as glacier altitude, location, orientation, debris coverage, surge activities, and interaction with glacial lakes, were interpreted in detail. The significant findings are as follows.

943 First, due to the heat conduction of the glacial drainage system, thick debris (1 5 m) could not 944 prevent the ablation. However, its attenuating effects were considerable. Second, some large glaciers surged again between 2000 and 2012. However, the magnitudes are much lower than in previous surges. We ascribed this process to the acceleration of englacial stress change and the enhancement of subglacial lubrication. Compared with non-surge glaciers, the surge glaciers have experienced a greater decline. Third, due to the thermal erosion of glacial lake water, the thinning of the glacier bodies connected to the lakes is very rapid. Due to the ice calving into the proglacial lakes, the glaciers recede at an abnormal rate. 
The terrain of the CTS is quite rough. Nevertheless, we have successfully retrieved the thickness changes of mountain glaciers, which demonstrates the potential of our approach. With the 953 availability of global TanDEM-X images, our approach will make considerable contributions to 954 better understanding the changes of mountain glaciers.

\section{Acknowledgement}

This research was supported by the National Natural Science Foundation of China (Nos.

Aizen, V.B., Kuzmichenok, V.A., Surazakov, A.B., Aizen, E.M. (2006). Glacier changes in the central and northern Tien Shan during the last 140 years based on surface and remote-sensing data. Annals of Glaciology, 43 , 202-213

Aizen, V.B., Kuzmichenok, V.A., Surazakov, A.B., Aizen, E.M. (2007). Glacier changes in the Tien Shan as determined from topographic and remotely sensed data. Global and Planetary Change, 56, 328-340.

Albert, T. H. (2002). Evaluation of remote sensing techniques for ice-area classification applied to the tropical Quelccaya Ice Cap, Peru. Polar Geography, 26(3), 210-226.

Arendt, A., Bliss, A., Bolch, T., Cogley, J.G., Gardner, A.S., Hagen, J.-O., et al. (2015). Randolph Glacier Inventory-A Dataset of Global Glacier Outlines: Version 5.0. Global Land Ice Measurements from Space, Boulder Colorado, USA. Digital Media.

Bamber, J.L. and Rivera, A. (2007). A review of remote sensing methods for glacier mass balance determination. Global and Planetary Change, 59, 138-148. 
Berthier, E., Arnaud, Y., Vincent, C., Rémy, F. (2006). Biases of SRTM in high-mountain areas. Implications for

977

the monitoring of glacier volume changes. Geophysical Research Letters, 33(8), 153-172.

Berthier, E., Arnaud, Y., Kumar, R., Ahmad, S., Wagnon, P., Chevallier, P. (2007). Remote sensing estimates of glacier mass balances in the Himachal Pradesh (Western Himalaya, India). Remote Sensing of Environment, 108, $327-338$.

David J. A., Marek, E., Stewart, S. R., Chris, O. (2015). Surficial geology and geomorphology of the Kumtor Gold Mine, Kyrgyzstan: human impacts on mountain glacier landsystems. Journal of Maps, DOI:10.1080/17445647.2015.1071720

Evans, D. and Gooster, L. (2005). Glacial Landsystems. London: Routledge, (Chapter 10).

Farinotti, D., Longuevergne, L., Moholdt, G., Duethmann, D., Mölg, T., Bolch, T., et al. (2015). Substantial glacier mass loss in the Tien Shan over the past 50 years. Nature Geoscience, 8, 716-723.

Farr, T.G. and Kobrick, M. (2000). Shuttle radar topography mission produces a wealth of data. Eos Trans. AGU, $81,583-583$

Flowers, G. E., Roux, N., Pimentel, S., Schoof, C. G. (2011). Present dynamics and future prognosis of a slowly surging glacier. The Cryosphere, 5, 299-313.

Fujita, K., Takeuchi, N., Nikitin, S.A., Surazakov, A.B., Okamoto, S., Aizen, V.B., et al. (2011). Favorable climatic regime for maintaining the present-day geometry of the Gregoriev Glacier, Inner Tien Shan. The Cryosphere, 5, $539-549$.

Gardelle, J., Berthier, E., Arnaud, Y. (2012). Impact of resolution and radar penetration on glacier elevation changes computed from DEM differencing. Journal of Glaciology, 58, 419-422.

Gardelle, J., Berthier, E., Arnaud, Y., Kääb, A. (2013). Region-wide glacier mass balances over the PamirKarakoram-Himalaya during 1999-2011. The Cryosphere, 7, 1263-1286.

Gardner, A. S., Moholdt, G., Cogley, J. G., Wouters, B., Arendt, A. A., Wahr, J., et al. (2013). A Reconciled Estimate of Glacier Contributions to Sea Level Rise: 2003 to 2009. Science, 340, 852-857.

Hagg, W., Mayer, C., Lambrecht, A., Kriegel, D., Aziov, E. (2013). Glacier changes in the Big Naryn basin, Central Tian Shan. Global and Planetary Change, 110(4), 40-50.

Hajnsek, I., Busche, T., Fiedler, H., Krieger, G., Buckreuss, S., Zink, M., et al. (2010). TanDEM-X Science Plan, 
1004 Hambrey, M. and Alean, J. (2004). Glaciers (Second Edition). Cambridge: Cambridge University Press, (Chapters 3, 1005 4).

1006 Höhle, J. and Höhle, M. (2009). Accuracy assessment of digital elevation models by means of robust statistical 1007 methods. ISPRS Journal of Photogrammetry and Remote Sensing. 64, 398-406.

1008 Jacob, T., Wahr, J., Pfeffer, W. T., Swenson, S. (2012). Recent contributions of glaciers and ice caps to sea level rise. 1009 Nature. 482, 514-518.

1010 Kääb, A. (2005). Remote sensing of mountain glaciers and permafrost creep. Zürich: Geographisches Institut der 1011 Universität Zürich, (Chapter 4).

1012 Kääb, A. (2008). Glacier volume changes using ASTER satellite stereo and ICESat GLAS Laser Altimetry. A Test 1013 Study on Edgeyøa, Eastern Svalbard. IEEE Transactions on Geoscience and Remote Sensing, 46(10), 2823-2830.

1014 Kääb, A., Berthier, E., Nuth, C., Gardelle, J., Arnaud, Y. (2012). Contrasting patterns of early twenty-first-century 1015 glacier mass change in the Himalayas. Nature, 488, 495-498.

1016 Khodakov, V.G. (1972). A calculation of ice ablation under the moraine layer. Data of Glaciological Studies, 20, $1017 \quad 105-108$

1018 Kutuzov, S. and Shahgedanova, M. (2009). Glacier retreat and climatic variability in the eastern Terskey-Alatoo, 1019 inner Tien Shan between the middle of the 19th century and beginning of the 21 st century. Global and Planetary 1020 Change, 69, 59-70.

1021 Li, J., Li, Z.W., Ding, X.L., Wang, Q.J., Zhu, J.J., Wang, C.C. (2014). Investigating mountain glacier motion with 1022 1023 Science Reviews, 138, 179-195.

1024 Li, X., Cheng, G.D., Jin, H.J., Kang, E.S., Che, T., Jin, R., et al. (2008). Cryospheric change in China. Global and 1025 Planetary Change, 62(3-4), 210-218.

1026 Lingle, C. S. and Fatland, D. R. (2003). Does englacial water storage drive temperate glacier surges? Annals of 1027 Glaciology, 36, 14-20.

1028 Liu, C.H., Xie, Z.C., Ergianuofu, M. (1998). Tien Shan glaciation (in Chinese). Beijing: Science Press, (Chapter 4).

1029 Liu, S.Y., Ding, Y.J., Shangguan, D.H., Zhang, Y., Li, J., Han, H. D., et al. (2006). Glacier retreat as a result of 
climate warming and increased precipitation in the Tarim river basin, northwest China. Annals of Glaciology, 43, $103191-96$.

1032 Mayer, C., Lambrecht, A., Hagg, W., Helm, A., Scharrer, K. (2008). Post-drainage ice dam response at Lake 1033 Merzbacher, Inylchek glacier, Kyrgyzstan. Geografiska Annaler: Series A, 90 (1), 87-96.

1034 Narama, C., Kääb, A., Duishonakunov, M., Abdrakhmatov, K. (2010). Spatial variability of resent glacier area 1035 changes in the Tien Shan Mountains, Central Asia, using Corona ( 1970), Landsat ( 2000), and ( 2007) satellite 1036

Nuimura, T., Sakai, A., Taniguchi, K., Nagai, H., Lamsal, D., Tsutaki, S., et al. (2015). The GAMDAM Glacier 1038 Inventory: a quality controlled inventory of Asian glaciers. The Cryosphere, 9, 849-864.

1039 Nuth, C. and Kääb, A. (2011). Co-registration and bias corrections of satellite elevation data sets for quantifying 1040 glacier thickness change. The Cryosphere, 5, 271-290.

1041 Osmonov, A., Bolch, T., Chen, X., Kurban, A., Guo, W.P. (2013). Glacier characteristics and changes in the Sary1042 Jaz River Basin (CTS, Kyrgyzstan) 1990-2010. Remote Sensing Letters, 4(8), 725-734.

1043 Paul, F. (2008). Calculation of glacier elevation changes with SRTM: is there an elevation-dependent bias? Journal 1044 of Glaciology, 54, 945-946.

1045 Paul, F., Bolch, T., Kääb, A., Nagler, T., Nuth, C., Scharrer, K., et al. (2013). The glaciers climate change initiative: 1046 Methods for creating glacier area, elevation change and velocity products. Remote Sensing of Environment, 162, $1047 \quad 408-426$

1048 Pieczonka, T., Bolch, T., Wei, J.F., Liu, S.Y. (2013). Heterogeneous mass loss of glaciers in the Aksu-Tarim 1049 Catchment (CTS) revealed by 1976 KH-9 Hexagon and 2009 SPOT-5 stereo imagery. Remote Sensing of 1050 Environment, 130, 233-244.

1051 Pieczonka, T. and Bolch, T. (2015). Region-wide glacier mass budgets and area changes for the CTS between 1052 1975 and 1999 using Hexagon KH-9 imagery. Global and Planetary Change, 128, 1-13.

1053 Quincey, D.J., Luckman, A., Benn, D. (2009). Quantification of Everest region glacier velocities between 1992 and 1054 2002, using satellite radar interferometry and feature tracking. Journal of Glaciology, 55(192), 596-606.

1055 Rabus, B., Eineder, M., Roth, A., Bamler, R. (2003). The Shuttle Radar Topography Mission-A new class of 1056 digital elevation models acquired by spaceborne radar. ISPRS Journal of Photogrammetry and Remote Sensing, 1057 57(4), 241-262. 
1059 Rodríguez, E., Morris, C.S., Belz, J.E. (2006). A Global assessment of the SRTM performance, Photogrammetric 1060 Engineering \& Remote Sensing, 72(3), 249-260.

1061 Shangguan, D.H., Bolch, T., Ding, Y. J., Kröhnert, M., Pieczonka, T., Wetzel, H.U., et al. (2015). Mass changes of 1062 Southern and Northern Inylchek Glacier, Central Tian Shan, Kyrgyzstan, during 1975 and 2007 derived from remote sensing data. The Cryosphere, 9, 703-717.

1064 Sheng, Y.P., Wang, G.Y., Ding, Y.J., Mao, W.Y., Liu, S.Y., Wang, S.D., et al. (2009a). Changes in glacier mass 1065 balance in watershed of Sary Jaz-Kumarik rivers of Tianshan Mountains in 1957-2006 and their impact on water 1066 resources and trend to end of the 21th Century (in Chinese with English abstract). Chinese Journal of Glaciology and Geocryology, 31(5), 792-800.

Sheng, Y.P., Wang, G.Y., Ding, Y.J., Su, H.C., Mao, W.Y., Wang, S.D., et al. (2009b). Changes in Merzbacher Lake 1069 of Inylchek Glacier and glacial flash floods in Aksu River Basin, Tianshan during the period of 1903-2009 (in 1070 Chinese with English abstract). Chinese Journal of Glaciology and Geocryology, 31(6), 993-1002.

1071 Shi Y.F., Huang, M.H., Yao, T.D., He, Y.Q. (2008). Glaciers and related environments in China. Beijing: Science 1072 Press, (Chapter 3).

1073 Sorg, A., Bolch, T., Stoffel, M., Solomina, O., Beniston, M. (2012). Climate change impacts on glaciers and runoff in Tien Shan (Central Asia). Nature Climate Change, DOI: 10.1038/NCLIMATE1592.

1075 Sørensen, L. S., Simonsen, S. B., Nielsen, K., Lucas-Picher, P., Spada, G., Adalgeirsdottir, G., et al. (2011). Mass 1076 balance of the Greenland ice sheet (2003-2008) from ICESat data - the impact of interpolation, sampling and firn 1077 density. The Cryosphere, 5, 173-186.

1078 Su, Z., Song, G.P., Wang, L.L. (1985). Glacial and meteorology in mountain Tuomuer district, Tianshan (in 1079 Chinese). Urumqi: Xinjiang People’s Publish House, (Chapter 1).

1080 Sun, M.P., Yao, X.J., Li, Z.Q., Li, J. (2012), Estimation of Tailan River Discharge in the Tianshan Mountains in the 108121 st Century. Progressus Inquisitiones De Mutatione Climatis (in Chinese), 8(5), 342-349.

1082 Unger-Shayesteh, K., Vorogushyn, S., Farinotti, D., Gafurov, A., Duethmann, D., Mandychev, A., et al. (2013). 1083 What do we know about past changes in the water cycle of Central Asian headwaters? A review. Global and 1084 Planetary Change, 110, Part A, 4-25.

1085 Wang, P.Y., Li, Z.Q., Li, H.L., Wang, W.B., Wang, F.T. (2011). Ice Surface-Elevation Change and Velocity of 
1086 Qingbingtan Glacier No.72 in the Tomor Region, Tianshan Mountains, Central Asia. Journal of Mountain Science, $10878,855-864$.

1088 WGMS (1991). Glacier mass balance bulletins -Bulletins No. 1 (1988-1989). IAHS(ICSI) /UNEP/ UNESCO, 1089 World Glacier Monitoring Service, Zurich, Switzerland. Available online at http://wgms.ch/products_gmbb/.

1090 WGMS (1999). Glacier mass balance bulletins -Bulletins No. 5 (1996-1997). IAHS(ICSI) /UNEP/ UNESCO, 1091 World Glacier Monitoring Service, Zurich, Switzerland. Available online at http://wgms.ch/products_gmbb/.

1092 WGMS (2015). Global Glacier Change Bulletin No. 1 (2012-2013). ICSU(WDS)/IUGG(IACS)/UNEP/UNESCO/ 1093 WMO, World Glacier Monitoring Service, Zurich, Switzerland, Doi:10.5904/wgms-fog-2015-11.

1094 Xie, C.W., Ding, Y.J., Chen, C.P., Han, T.D. (2007). Study on the change of Keqikaer Glacier during the last 30 1095 years, Mt. Tuomuer, Western China. Environmental Geology, 51, 1651-1170.

1096 Xie, Z.C. and Liu, C.H. (2010). Introduction of Glaciology (in Chinese). Beijing : Science Press, (Chapters 5, 7).

1097 Yao, T.D., Thompson, L., Yang, W., Yu, W.S., Gao, Y., Guo, X.J., et al. (2012). Different glacier status with 1098 atmospheric circulations in Tibetan Plateau and surroundings. Nature Climate Change, 2(9), 663-667. 